\title{
Genetic Variants of the Human Dipeptide Transporter PEPT1
}

Pascale Anderle, Carsten Uhd Nielsen, Julia Pinsonneault, Pernille Lindskov Krog, Birger Brodin, and Wolfgang Sadée

Department of Pharmacology, Program in Pharmacogenomics, College of Medicine and Public Health, Ohio State University, Columbus OH, USA (P.A., J.P., W.S.)

ISREC, Epalinges s/Lausanne, Switzerland (P.A.)

Molecular Biopharmaceutics, Department of Pharmaceutics and Analytical Chemistry, The Danish University of Pharmaceutical Sciences, 2-Universitetsparken, DK-2100 Copenhagen, Denmark (C.U.N., P.L.K., B.B.)

Plasma Membrane Transporter Group, Department of Biopharmaceutical Sciences, University of California, San Francisco, San Francisco, CA (W.S.) 
JPET \#94615

\section{a) Running title:}

Genetic Variants of the Human Dipeptide Transporter PEPT1

\section{b ) Address of corresponding author:}

Prof. Wolfgang Sadée

Department of Pharmacology

OSU Program in Pharmacogenomics

5078 Graves Hall

333 W. 10th Avenue

Columbus, $\mathrm{OH} 43210$

Phone: (614) 292-1597

Fax: (614) 292-7232

Email: sadee-1@medctr.osu.edu

\section{c) Statistical information}

Number of text pages: 31

Number of tables: 6

Number of figures: 6

Number of references: 32

Number of words in Abstract: 249

Number of words in Introduction: 656

Number of words in Discussion: 1496

\section{d) Nonstandard abbreviations}

hPepT1, human peptide transporter 1;

Azidothymidine, AZT;

L-valacyclovir, VAC;

2-(N-morpholino) ethanesulfonic acid ,MES;

$\mathrm{N}$-[2-hydroxyethyl]piperazine- $\mathrm{N}^{\prime}$-[2-ethanesulfonate], HEPES;

non-essenmtial amino acids, NEAA;

Dulbecco's Modified Eagle's Medium, DME;

HPLC, high-performance liquid chromatography;

HEK, human embryonic kidney.

\section{e) Recommended section assignment}

ABSORPTION, DISTRIBUTION, METABOLISM, AND EXCRETION

or GASTROINTESTINAL, HEPATIC, PULMONARY, AND RENAL 
JPET \#94615

\section{ABSTRACT}

We tested whether genetic polymorphisms affect activity of the dipeptide transporter PEPT1, which mediates bioavailability of peptidomimetic drugs. All 23 exons and adjoining intronic sections of PEPT1 (SLC15A1) were sequenced in 247 individuals of various ethnic origins (Coriell collection). Of 38 single nucleotide polymorphisms (SNPs), 21 occurred in intronic and non-coding regions, and 17 in exonic coding region, of which 9 were nonsynonymous. Eight nonsynonymous variants were cloned into expression vectors and functionally characterized after transient transfection into Cos7 and $\mathrm{CHO}$ cells. None of the variants had altered transport activity for various ligands, supporting previous results, except for the new, low frequency PEPT1-F28Y. This variant displayed significantly reduced cephalexin uptake attributable to increased $\mathrm{K}_{\mathrm{m}}$. Altered $\mathrm{pH}$-dependence of substrate transport suggested a role for $\mathrm{F} 28 \mathrm{Y}$ in $\mathrm{H}^{+}$-driven translocation. Haplotype analysis revealed significant differences among ethnic populations. To search for cis-acting polymorphisms affecting transcription and mRNA processing, we measured allelic PEPT1 mRNA expression in human intestinal biopsy samples, using a frequent marker SNP in exon 17. Of 24 heterozygous samples, significant differences in allelic mRNA levels of 20$30 \%$ were observed in 7 tissues. However, the small difference suggests that cis-acting regulatory factors have only limited effects on transporter activity. We also measured the relative formation of a splice variant (PEPT1-RF). PEPT1-RF mRNA levels ranged from 2 to $44 \%$ of total PEPT1-related mRNA, with potential consequences for drug absorption. Together with previous results, this study reveals a relatively low level of genetic variability, in polymorphisms affecting both protein function and gene regulation. 
JPET \#94615

\section{INTRODUCTION}

Endogenous peptides with regulatory functions serve as hormones, neuropeptides or neurotransmitters, and cytokines, stimulating interest in their therapeutic use. Moreover, small peptides represent an important nutritional source of amino acids. Membrane transporters such as the proton-coupled oligopeptide transporters, PEPT1 and PEPT2 (SLC15A1 and SLC15A2), facilitate absorption and distribution of small peptides (2-3 residues) and polar peptoid drugs that would otherwise not cross lipid membranes. The intestinal PEPT1 transporter is involved in carrier-mediated uptake of peptide-like drugs such as cephalexin, ACE-inhibitors, and 5'-amino acid esters of the antiviral nucleosides, acyclovir, AZT, and ganciclovir (Ganapathy et al., 1995; Han et al., 1998). Bioavailablility of the prodrug L-valacyclovir (VAC) is substantially increased by PEPT1 transport activity.

Response to drug therapy varies in-between patients, in part because of genetic differences among individuals. Polymorphisms of drug receptors, metabolizing enzymes, and transporters each can affect therapeutic efficacy (Licinio and Wong, 2002). While the effect of genetic variants has been well documented for drug metabolizing enzymes, drug transporters have been less thoroughly studied (Dai and Sadee, 2005). Yet, recent results demonstrate a pervasive role for genetic variants of several membrane transporters, such as MDR1 (Hoffmeyer et al., 2000). For the PEPT1 substrate VAC, a significantly larger interindividual than intraindividual variability in intestinal absorption suggests the presence of genetic factors, potentially involving PEPT1 (Phan et al., 2003). In a previous sequencing study of PEPT1 involving 44 ethnically diverse individuals, 13 SNPs had been located in the coding region of PEPT1 (Zhang et al., 2004). Functional characterizations of the nine non-synonymous SNPs revealed that only one rare variant had reduced transport activity as a result of reduced protein expression. The UCSF Membrane Transporter Group had also performed a more extensive sequence analysis of PEPT1, of which the results are publicly available (http://pharmacogenetics.ucsf.edu/set1/index.html\#SLC15A1). We had independently prepared mutant PEPT1 plasmids for functional in vitro analysis based on these more extensive sequence data, and have now confirmed and extended the functional 


\section{JPET \#94615}

analysis of PEPT1 variants. Moreover, we have sequenced not only PEPT1 coding regions but also adjoining intronic regions which may be subject to alternative splicing. The large sample size also permits detailed analysis of haplotype structures and ethnic distributions of the main alleles and haplotypes.

Genomic surveys have revealed that regulatory polymorphisms acting in cis (i.e., on the transcription of the gene they are located in) represent a main source of human phenotypic variability (Rockman and Wray, 2002; Johnson et al., 2005). Moreover, polymorphisms in transcribed regions of a gene can affect mRNA processing and turnover (Johnson et al., 2005). Hoffmeyer et al. (Hoffmeyer et al., 2000) for instance observed that a synonymous SNP in $A B C B 1$ correlates with expression levels and in vivo activity of the protein product of $A B C B 1$. We have now demonstrated that this SNP (C3435T) alters mRNA turnover, because of changes in mRNA folding (Wang et al., 2005). Nearly half of all human genes are alternatively spliced (Modrek and Lee, 2002), which can be subject to genetic variations. Yet a majority of these cisacting polymorphisms has yet to be discovered. We use here a quantitative analysis of each of two PEPT1 alleles in small intestines, the main site of expression, as an integrative measure of all cis-acting polymorphisms affecting gene regulation and mRNA processing, as previously shown for PEPT2 (Pinsonneault et al., 2004). Any significant differences in allelic ratios between genomic DNA and mRNA (measured as cDNA) reveals the presence of allelic expression imbalance (AEI) (Yan et al., 2002) and hence the presence of cis-acting factors. Moreover, we have measured the relative formation of a splice variant, PEPT1-RF (Urtti et al., 2001),previously shown in vitro to regulate $\mathrm{H}^{+}$-dependent PEPT1 transport (Saito et al., 1997). Taken together, this study provides a quantitative assessment of genetic variability of PEPT1, providing details on a new but rare functional variant in the coding region, while showing that genetic factors overall appear to play only a small role in determining interindividual variability in PEPT1 transporter activity in intestines. 
JPET \#94615

\section{MATERIAL AND METHODS}

\section{Material}

Cephalexin, Leu-Ala, enalapril maleate, bovine serum albumin (BSA), 2-(N-morpholino) ethanesulfonic acid (MES), $\mathrm{N}$-[2-hydroxyethyl]piperazine- $\mathrm{N}^{\prime}$-[2-ethanesulfonate] (HEPES), glycylsarcosine (Gly-Sar), and glycylproline (Gly-Pro) were purchased from Sigma (St. Louis, MO). VAC was a gift from Dr. G. Amidon, University of Michigan. $\left[{ }^{14} \mathrm{C}\right]-\mathrm{Gly}-\mathrm{Sar}$ (specific activity $49.94 \mathrm{mCi} \mathrm{mmol}$ ) and $\left[{ }^{3} \mathrm{H}\right]-$ Mannitol (specific activity $20 \mathrm{Ci} \mathrm{mmol}$ ) were from NEN (Boston, MA, USA). Media for $\mathrm{CHO}$ and Cos7 cell culture were from Cell Culture Facility at UCSF (San Francisco, CA), and for HEK 293 cells from Life Technologies (Høje Taastrup, Denmark). Alexa 488-conjugated goat anti-rabbit IgG, alexa 488-conjugated phalloidin, and propidium iodide were from Molecular Probes (Eugene, OR, USA). Rabbit-anti-PEPT1, raised against a peptide corresponding to the last 15 carboxy-terminal amino acid residues of the human peptide transporter PEPT1, was used as previously described (Nielsen et al., 2001). Other chemicals were either analytical or HPLC grade.

\section{Genotyping and variant construction.}

Primers for exons and adjoining intron regions (ca. $50 \mathrm{bp}$ ) for PEPT1 (NCBI reference sequence: NM_005073) were designed using the Virtual Genome center website at http://alces.med.umn.edu/VGC.html and ordered from Operon (Alameda, CA). A collection of 247 ethnically identified genomic DNA samples were obtained from the Coriell Institute of Medicine and used to screen for PEPT1 variants. PCR was performed in split $20 \mu \mathrm{L}$ reactions using TaqGold on the GeneAmp 9700 thermocycler from PE. One of three PCR protocols was chosen based on an optimization performed prior to amplifying all 247 samples, adding glycerol or DMSO or both to a reaction for optimization of product yield. PCR products were tested by agarose gel electrophoresis $(2 \%, 150 \mathrm{~V}, 35$ minutes). Three reaction products were pooled for dHPLC analysis on a Varian HPLC with Varian Helix columns. Amplicon sequences were analyzed with a dHPLC melt program (http://insertion.stanford.edu/melt.html) to establish optimal dHPLC conditions. If a 


\section{JPET \#94615}

sample scored positive, the three individual amplicons were treated with 2 units SAP and Exol (from USB) and sequenced using ABI BigDye v2, cleaned with 96-well gel filtration blocks from Edge BioSystems, and run on the ABI 3700 DNA Analyzer. In the following cases, dHPLC was skipped and all samples were individually sequenced: a. A known SNP exists with an allelic frequency greater than $33 \%$. b. dHPLC revealed a common polymorphism. c. dHPLC results were not scoreable. d. An additive such as DMSO or glycerol was used in PCR. Sequences were scored with Sequencher v4. All singleton SNPs were verified with an independent PCR reaction followed by and sequencing.

\section{Haplotype analysis}

Haplotype were determined using the PHASE algorithm. The method regards the unknown haplotypes as unobserved random quantities and aims to evaluate their conditional distribution in light of the genotype data (Stephens et al., 2001).

\section{Cell culture and transfection}

Monkey Cos7, Chinese hamster ovary cells $(\mathrm{CHO})$, and human embryonic kidney cells (HEK 293) were obtained from American Type Culture Collection. Cos7 cells were grown in DME H16/F-12 medium with NEAA (1:1) containing 10\% fetal bovine serum and penicillin (100 units $/ \mathrm{mL})$ and streptomycin $(100 \mu \mathrm{g} / \mathrm{mL})$ at $37^{\circ} \mathrm{C}$ in a humidified atmosphere with $5 \% \mathrm{CO}_{2}$. $\mathrm{CHO}$ cells were grown in F-12 medium with NEAA containing $10 \%$ fetal bovine serum under the same conditions as Cos7 cells. Cos7 and $\mathrm{CHO}$ cells were plated in 12-well plates at $3.5 \times 10^{5}$ cells/well and cultured for $24 \mathrm{~h}$. The medium was replaced by a mixture of $3 \mu \mathrm{g}$ plasmid (pcDNA 3.1 containing wild-type PEPT1 or its variants or no insert) and $3 \mu \mathrm{L}$ LipoFectamine 2000 (Invitrogen, $\mathrm{CA}$ ) in $200 \mu \mathrm{L}$ OptiMem. The cells were incubated for 6 hours at $37^{\circ} \mathrm{C}$, and after centrifugation the supernatant was replaced with fresh medium. HEK 293 cells were grown at $37^{\circ} \mathrm{C}$, in an atmosphere of $5 \% \mathrm{CO}_{2}$ and $90 \%$ relative humidity in standard growth media: Modified Eagle's Medium (MEM) supplemented with $10 \%$ fetal bovine serum, $1 \mathrm{mM}$ sodium pyruvate, $1 \%$ NEAA, $2 \mathrm{mM} \mathrm{L-glutamine,} 100 \mathrm{U} \cdot \mathrm{ml}^{-1}$ penicillin and $100 \mu \mathrm{g} \cdot \mathrm{ml}^{-1}$ streptomycin. Cells were seeded at a density of $8 \times 10^{4}$ cells $\cdot \mathrm{cm}^{-2}$ onto polylysine-coated polycarbonate wells with a growth area of 3.8 
JPET \#94615

$\mathrm{cm}^{2}$. HEK 293 were transfected once they reached approximately $50 \%$ confluency using Jet-PEI (Qbiogene, Carlsbab, CA) according to the manufactures protocol. pcDNA 3.1 plasmid-constructs were transiently transfected into HEK 293 cells using Jet-PEI. 24h after transfection, the cell monolayers were used for experiments.

\section{Uptake studies in cell culture}

Uptake studies: In Cos7 and $\mathrm{CHO}$ cells uptake studies were performed 24 hours after transfection. Cells were washed twice at $37^{\circ} \mathrm{C}$ with Krebs' phosphate buffer $(1 \mathrm{mM} \mathrm{CaCl}, 1 \mathrm{mM}$, $\mathrm{MgCl}_{2}, 150 \mathrm{mM} \mathrm{NaCl}, 3 \mathrm{mM} \mathrm{KCl}, 1 \mathrm{mM} \mathrm{NaH}{ }_{2} \mathrm{PO}_{4}, 5 \mathrm{mM} \mathrm{MES}$ and $5 \mathrm{mM}$ Glucose, $\mathrm{pH}$ 6.0), and washing buffer was replaced with buffer containing $1.44 \mu \mathrm{M}$ cephalexin. HEK 293 cells were placed on a shaking plate, pre-heated to $37^{\circ} \mathrm{C}$ (SWIP, EB) and allowed to equilibrate for 15 min in HBSS pH 7.4 buffer solution. Uptake of $\left[{ }^{14} \mathrm{C}\right]$-Gly-Sar and of $\left[{ }^{3} \mathrm{H}\right]$-mannitol was measured in Hanks Balanced Salt solution (HBSS) supplemented with 0.05\% BSA and buffered with $10 \mathrm{mM}$ HEPES to the appropriate $\mathrm{pH}$ value. The experiment was started by adding fresh buffer containing Gly-Sar $(20-5000 \mu \mathrm{M})$ and $0.5 \mu \mathrm{Ci}\left[{ }^{14} \mathrm{C}\right]$-Gly-Sar per well. $0.5 \mu \mathrm{Ci}\left[{ }^{3} \mathrm{H}\right]$-mannitol per well was added to the solution as a marker of extracellular space. The uptake of Gly-Sar in transiently transfected cells was linear for 5 to $15 \mathrm{~min}$, depending on the cells used. Uptake experiments were terminated after 5 to 15 minutes by removing the uptake medium, followed by three washes of the monolayers with ice-cold HBSS. The cells were detached from the well with $0.1 \%$ TritonX in phosphate buffered saline. Samples were divided for protein analysis, and radioactivity determinations using liquid scintillation counting. Experiments were performed using 4-9 individual transfections.

Inhibition studies: For inhibition studies in Cos7 and $\mathrm{CHO}$ cells, the $0.5 \mu \mathrm{Ci}\left[{ }^{14} \mathrm{C}\right]-\mathrm{Gly}$-Sar was incubated together with increasing concentrations of the test compound $\left(0.1 \mu \mathrm{M}-10^{6} \mu \mathrm{M}\right.$ for GlySar and Leu-Ala, $0.1-5 \times 10^{5} \mu \mathrm{M}$ for enalapril maleate, $0.1-10^{5} \mu \mathrm{M}$ for VAC). After 60 min drug solution was removed and cells were washed twice with chilled buffer. To each well $0.5 \mathrm{~mL}$ MilliQ water was added and cells were incubated on a shaker for 2 hours and harvested by aspirating 4 times with a syringe. $20 \mu \mathrm{L}$ was removed from the suspension for protein concentration 
JPET \#94615

measurements using the BioRad protein assay (Hercules, CA). The suspension was then centrifuged for $10 \mathrm{~min}$ at 10,000 rpm, the supernatant removed and used for HPLC analysis. For HEK 293 cells the experiment was initiated by adding $0.5 \mathrm{~mL}$ MES-buffer (pH 6.0) containing 0.5 $\mu \mathrm{Ci} / \mathrm{ml}\left[{ }^{14} \mathrm{C}\right]$-Gly-Sar $(20 \mu \mathrm{M})$ and various amounts of unlabeled test compounds to the transfected HEK 293 cells. From this point on, the affinity experiment was similar to the Gly-Sar uptake experiment. Affinity experiments were performed using cells from 4 - 8 individual transfections.

pH-dependent uptake: We investigated the $\mathrm{pH}$-dependence of Gly-Sar transport via the wildtype PEPT1 and variant F28Y from pH 5 to 7.4 . HEK 293 cells were equilibrated with HEPES buffer $\mathrm{pH} 7.4$ for 15 min. The medium was then changed to MES buffer solutions with a pH of 5.0; 5.5; or 6.0 , or HEPES buffer solutions with a $\mathrm{pH}$ of $6.5 ; 7.0$; or 7.4. Gly-Sar uptake into the cells at concentrations of $20 \mu \mathrm{M}$ or $5 \mathrm{mM}$ was then measured over a 5 min period. HEK 293 cells were then treated as described above. Experiments were performed with 6 individual transfections.

\section{Protein extraction and determination}

HEK 293 cells detached from the cell culture dishes were placed in Eppendorf tubes with NP-40 lysis buffer (10 mM Tris-HCl (pH 7.4), 0.25 M sucrose, 1 mM EDTA, 1 mM EGTA, 2 \% NP-40). The tubes were centrifuged at $10000 \mathrm{~g}$ for 10 minutes. The protein content in lysates free of cellular debris was determined by the method of Bradford, using a Bio-Rad protein assay kit according to the manufacturers' instructions (Bio-Rad, Hemel Hempstead, UK).

\section{High pressure liquid chromatography}

The HPLC system used was a Shimadzu HPLC SCL-10A system. Cephalexin was separated by reversed phase chromatography on a RP 18 Alltima column (100 A, $5 \mu \mathrm{m}) 25 \mathrm{~cm} \times 4.6 \mathrm{~mm}$ (Deerfield, IL) at room temperature and detected in the UV at $210 \mathrm{~nm}$. The mobile phase consisted of $20 \%$ acetonitrile and $0.1 \%$ phosphoric acid in water. The flow rate was $1.0 \mathrm{~mL} \mathrm{~min}^{-}$ 1. 
JPET \#94615

\section{Confocal laser scanning microscopy (CLSM)}

PEPT1 localization and expression in transiently transfected HEK 293 cells was studied using CLSM. Cells grown on filters were rinsed in HBSS buffer, fixed for 10 min in $3 \%$ paraformaldehyde solution in HBSS and permeabilized for 5 minutes in $0.1 \%$ Triton X-100 in PBS, followed by blocking overnight with $2 \%$ BSA in PBS. After rinsing in PBS, cells were treated with $100 \mu \mathrm{g} \mathrm{ml}^{-1}$ RNAse in 2XSSC buffer solution (300 mM NaCl, $30 \mathrm{mM}$ sodium citrate, $\mathrm{pH}$ 7.0) for 20 minutes. PEPT1 localization and expression was studied by immunostaining. After fixation and permeabilization, cells were incubated with anti-PEPT1 (1:200) antibody for 2 hours. The filters were rinsed in PBS and incubated with secondary antibody (Alexa 488-conjugated goat anti-rabbit $\lg G$ ) for 90 minutes, followed by RNAse treatment and propidium iodide counterstaining. All preparation steps were performed at room temperature $\left(20^{\circ} \mathrm{C}\right)$. Filters were mounted on coverslips and confocal imaging was performed on a Zeiss LSM 510 confocal laser scanning microscope, using a Zeiss plan apochromat $63 x$ oil immersion objective with a numerical aperture of 1.4. Fluorophores were excited using an argon laser line at $488 \mathrm{~nm}$ (filter: BP 505-550) and a HeNe laser line at $543 \mathrm{~nm}$ (filter: LP 560).

\section{Data Analysis}

Total uptake of Gly-Sar in transfected HEK 293 cells was corrected for non-cellular uptake using mannitol as previously described (Bravo et al., 2004) and for the uptake of Gly-Sar in mock transfected HEK 293 cells. The cellular carrier-mediated uptake as a function of apical Gly-Sar concentration was fitted to a Michaelis-Menten type equation (Equation 1),

$V=\frac{V_{\max } \times[S]}{K_{m}+[S]}$

Equation 1

where $\mathrm{V}=$ uptake rate $\left(\mathrm{pmol} \times \mathrm{mg}\right.$ protein $\left.^{-1} \times \mathrm{min}^{-1}\right), \mathrm{V}_{\max }=$ maximum uptake rate $(\mathrm{pmol} \times \mathrm{mg}$ $\left.\operatorname{protein}^{-1} \times \min ^{-1}\right), \mathrm{K}_{\mathrm{m}}=$ the Michaelis-Menten constant (mM), [S] = Gly-Sar concentration (mM). 


\section{JPET \#94615}

The $\mathrm{IC}_{50}$ values were determined from the dose-response inhibition curves. These values were calculated with the SigmaPlot software as described earlier (Covitz et al., 1996).

Values are given as mean \pm SD. The statistical significance of the results was determined using two-tailed paired Students t-test. $\mathrm{P}<0.05$ was considered significant. ${ }^{*} \mathrm{P}<0.05{ }^{* *} \mathrm{P}<0.01$ *** $\mathrm{P}<0.001$.

Analysis of sequence variations and nucleotide diversity. The neutral parameter $\theta$, the nucleotide diversity $\pi$ and the Tajima variable $D$ were calculated as described by (Tajima, 1989). The nucleotide diversity $\pi$ is the average number of pair-wise nucleotide differences between sequences in a sample. It depends on both the number of polymorphic sites and their frequency. The neutral parameter $\theta$ is based on the number of polymorphic sites in a sample of sequences drawn at random from a population. Thus, $\pi$ takes into account the frequencies at which polymorphisms are present in the sample, while $\theta$ is based solely on the observed number of segregating sites. The difference between $\pi$ and $\theta$, expressed by the Tajima's $D$ statistics, is used to detect departures from the standard neutral model (Stephens et al., 2001). A negative D value can be evidence for selection of one specific allele over alternate alleles. If, however, the majority of genes have a negative $D$ it could mean that the human study population underwent a recent expansion (Stephens et al., 2001).

\section{SNaPshot assay and quantitative analysis of allelic ratios in genomic DNA and mRNA in small intestinal samples}

56 biopsies of small intestine were obtained from the Cooperative Human Tissue Network at the Ohio State University. Tissues were obtained from the duodenum, the jejunum, the ileum, or unspecified small intestines. Most tissues were frozen between 15 and 30 minutes post-biopsy, although some had longer intervals ( 1 - 3 hours). Genomic DNA and RNA were extracted from each sample as described (Pinsonneault et al., 2004). In short, frozen tissue samples were pulverized under liquid nitrogen. The frozen powder was portioned into aliquots for DNA and RNA extractions. DNA was prepared by digestion of the pellet or frozen powder with sodium dodecyl sulfate and proteinase $\mathrm{K}$ followed by sodium chloride precipitation of proteins (Miller et al., 1988). 
JPET \#94615

The DNA in the supernatant was further purified and recovered by ethanol precipitation. For RNA preparation, the starting material was homogenized in TRIzol TM reagent (monophasic solution of phenol and guanidine isothiocyanate) (Invitrogen, Carlesbad, CA), and extracted with chloroform. The RNA was recovered by precipitation with isopropanol followed by centrifugation. For additional purification, the RNA precipitate was dissolved in RNase free water or Qiagen buffer (Qiagen, Valenia, CA), then extracted using Qiagen RNeasy ${ }^{\mathrm{TM}}$ columns according to the manufacturers instructions. Complementary DNA (cDNA) was generated from the mRNA by Superscript II reverse transcriptase (Invitrogen) employing oligo-dT and a PEPT1-specific reverse primer (ACACTAGAAGCGTGTGGCGTT).

SNaPshot is a primer extension method we have adapted for analysis on the $A B I 3730$, with a few modifications needed to accommodate data handling. We selected an abundant marker SNP (synonymous) in the transcribed region of PEPT1 (rs1339067, exon 17 position 78, T1347T). All 56 samples were first genotyped and then 24 heterozygous samples selected for allele-specific mRNA analysis. A stretch of genomic DNA ( 70 bp's) or cDNA, generated from mRNA, containing the marker SNP, was amplified by PCR, and the allelic ratio was measured in heterozygous samples by primer extension using fluorescently labeled terminator nucleotides, as previously described for PEPT2 (Pinsonneault et al., 2004). Genomic DNA serves as an internal control compared with amplification of cDNA of the same samples. Standard PCR conditions were used on $15 \mu \mathrm{l}$ reactions. Amplification conditions consisted of 35 cycles of denaturation at $95^{\circ} \mathrm{C}$ for 30 seconds, then primer annealing at $60^{\circ} \mathrm{C}$ for 1 minute, followed by extension at $72^{\circ} \mathrm{C}$ for 1 minute. (PEPT1 exon 17 amplification primer pairs: forward primer: ACATTTCTTCTCCTGGATCACCA, reverse primer ACACTAGAAGCGTGTGGCGTT). After amplification, the reactions were treated with exonuclease I and bacterial Antarctic alkaline phosphatase (New England Biolabs, Beverly, MA). For the primer extension, two separate genespecific primers (one for each strand) were designed with the 3'-end one base from the SNP position (PEPT1 exon 17, forward extension primer: CTGGATCACCAGTCACTGC) and PEPT1 exon 17, reverse extension primer: CTGCTTGAAGTCGTCAGTTAC. SNaPshot ${ }^{\mathrm{TM}}$ reagent from Applied Biosystems was used to incorporate a single fluorescently-labeled dideoxynucleotide to 
JPET \#94615

the 3' end of the primer in a template-dependent manner. The final primer extension reactions were run on an $\mathrm{ABI} 3730$ capillary electrophoresis DNA instrument, and analyzed with Gene Mapper ${ }^{\mathrm{TM}} 3.0(\mathrm{ABI})$ software. The peak area is proportional to the amount of each amplified allele. Since differing fluorophores may influence nucleotide incorporation, migration rates, and fluorescent yields, the peak areas are not identical between two alleles present in equal abundance in genomic DNAs, which was normalized to a ratio of 1. mRNA/cDNA ratios were corrected accordingly, by dividing the observed allelic mRNA/cDNA ratios for each sample by the mean of the allelic ratios observed for genomic DNA across all samples (none of the samples showed a significant difference in the genomic DNA ratio compared the mean, indicating the absence of any gene dosage effects). The cDNA results are averages ( \pm S.D.) of 8 separate experiments (4 with each extension primer), normalized to genomic DNA. Significant deviations from unity in the normalized mRNA/cDNA ratios reveal the presence of cis-acting factors affecting transcription and/or mRNA processing (allelic expression imbalance (AEI).

\section{RT-PCR of PEPT1 splice variant.}

cDNA preparations from 32 intestinal samples were also used for analysis of the RF splice variant, which consists of exons 3 - 7 (where exons 3 and 7 are partially shared with full-length wildtype PEPT1), and one additional exon 7' further downstream (located between exons 18 and 19) (Urtti et al., 2001) http://www.aapspharmsci.org/view.asp?art=ps030106). PCR was performed on cDNA samples using SYBR green dye on an $A B I 7000$ sequence detection system (Applied Biosystems, Foster City, CA, USA). PCR $(21 \mu \mathrm{L})$ in standard 96-well plates with heatactivated Taq DNA polymerase and SYBR Green. SYBR green fluorescence was measured after each cycle. Primers specific for each splice variant were combined with a common primer from exon 7. (Forward primer: GGCTATTAATGCTGGAAGTTTGC, reverse primer: AGACCAACAGAAGTTCCTTTCAGG, full-length primer: TTGTTGAACTCTGAGCATGGGT). Each reaction was replicated once. Cycle thresholds (Ct), at which an increase in reporter fluorescence above a baseline signal is detected, were determined with ABI 7000 SDS software. Replicate cycle thresholds were averaged. Approximate expression 


\section{JPET \#94615}

levels of each splice variant in each sample were determined $[X]=1 / 2^{\mathrm{Ct}}$. Relative abundances of full length to RF in each sample were calculated as ratios and converted to percentages. 
JPET \#94615

\section{RESULTS}

\section{Identification of PEPT1 variants}

We screened all 23 exons and adjoining intronic regions of PEPT1 in a collection of 247 individuals from different ethnic groups. This data set is available at the PharmGKB and UCSF

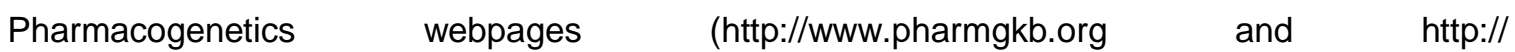
pharmacogenetics.uncsf.edu). Thirty-eight variant sites were identified (cf. Table 1). Of these 21 were located in the intronic or non-coding region. In the exonic coding regions, 9 of the detected single nucleotide polymorphism sites were non-synonymous and 8 were synonymous. Five SNPs were located in the transmembrane region, and the remaining 11 SNPs in the extracellular loops, with no SNPs detected in the intracellular loops (cf. Figure 1).

For some SNPs ethnic differences in distribution were observed. One non-synonymous (exon 17, SNP\#2) and three intronic SNPs (exon 1, SNP\#4, exon 15, SNP\#1, exon 21, SNP\# 1) differed at least twofold between ethnic groups, compared to mean allele frequency (cf.Table 1).

We analyzed the sequence data to detect any evolutionary trends suggesting selection pressures for genetic variants. Table 2 summarizes estimates of the neutral parameter $\theta$, nucleotide diversity $\pi$, and the variable Tajima's $D$ calculated for the entire sample and for each ethnic group. In all ethnic populations the values for the nucleotide diversity $\pi$ was consistently lower than the neutral parameter $\theta$. The difference between $\pi$ and $\theta$ can be expressed by the Tajima's D statistics used for detecting departures from the standard neutral evolutionary model (Stephens et al., 2001). African Americans had the highest neutral parameter value. The neutral parameter for the entire population was greater than that of the individual subpopulation, which is consistent with the existence of population substructure in this sample set.

\section{Haplotype analysis}

Using the PHASE algorithm, 107 distinct haplotypes emerged over 10 PHASE runs of which 24 were unambiguous haplotypes (i.e., were derived from homozygotes and single-site heterozygotes). Of these, 17 had a frequency of $1 \%$, accounting for $82.9 \%$ of all haplotypes 
JPET \#94615

(Table 3). The two most common haplotypes 1 and 2 were more frequent in Caucasians than African Americans. On the other hand, 10 out of the remaining 15 haplotypes were more frequent in African Americans, showing greater sequence diversity in this population.

\section{Functional characterization of PEPT1 variants}

Eight non-synonymous variants were functionally characterized to study the phenotypic influence of genetic variation of the PEPT1 transporter. As a first screen the uptake of cephalexin was investigated in transiently transfected Cos7 and $\mathrm{CHO}$ cells (Figure 2). Reduced cephalexin uptake compared to wild-type transfected cells was observed only in cells transiently transfected with variant F28Y. Next, we examined concentration-dependent Gly-Sar uptake for 15 min at pH 6.0 in transiently transfected HEK 293 cells. Figure 3 illustrates the obtained saturation curves with accompanying fits to equation 1 . The fitted values for $K_{m}$ were as follows: WT: $2.8 \pm 0.5 \mathrm{mM}$, F28Y: $3.2 \pm 0.7 \mathrm{mM}, \mathrm{S} 117 \mathrm{~N}: 2.5 \pm 0.6 \mathrm{mM}, \mathrm{G} 419 \mathrm{~A}: 2.7 \pm 0.6 \mathrm{mM}$. The $\mathrm{V}_{\max }$ values for Gly-Sar uptake were between $1.5 \pm 0.2-1.8 \pm 0.2 \mathrm{nmol} / \mathrm{mg}$ protein $/ \mathrm{min}$. The variants did not show any functional differences as judged from the kinetic parameters $K_{m}$ and $V_{\max }$, although the F28Y variant had tendency towards a higher $\mathrm{K}_{\mathrm{m}}$ value (Table 4). However, uptake studies of Gly-Sar at a low substrate concentration $(20 \mu \mathrm{M})$ revealed functional differences between the variants (Figure 4). At all pH levels, PEPT1-mediated uptake of Gly-Sar was significantly lower for the F28Y variant compared to WT, S117N and G419A (Figure 4). For the latter three, the uptake increased as the extracellular $\mathrm{pH}$ was lowered from 7.4 to 5 . On the other hand, differences between wild-type and F28Y varied with $\mathrm{pH}$ with a maximum at $\mathrm{pH} 5.5$ - 6.0. The $\mathrm{pH}$ dependent Gly-Sar uptake experiments were repeated under identical conditions except for using $5 \mathrm{mM}$ Gly-Sar instead of $20 \mu \mathrm{M}$. Under these high substrate conditions, both WT and the PEPT1 variants all showed similar absolute uptake rates and similar uptake patterns as a function of $\mathrm{pH}$ (data not shown).

To explore the transport kinetics further, we investigated the concentration-dependent uptake of Gly-Sar in HEK cells transiently transfected with F28Y and WT using a shorter incubation time (5 $\min$ ) at $\mathrm{pH} 6.0$, and at 5.0, where the difference in uptake of $20 \mu \mathrm{M}$ Gly-Sar between WT and F28Y was greatest (Table 4). The $\mathrm{K}_{\mathrm{m}}$ value for F28Y was significantly higher than the $\mathrm{K}_{\mathrm{m}}$ value for WT at both $\mathrm{pH} 5$ and 6 with no differences in the $\mathrm{V}_{\max }$ values. 
JPET \#94615

To study substrate selectivity, competitive inhibition of cephalexin uptake was tested with enalapril maleate, VAC, and Leu-Ala. The $\mathrm{IC}_{50}$ values of enalapril maleate $(2.1 \mathrm{mM})$, VAC (1.2 $\mathrm{mM})$, and Leu-Ala $(0.67 \mathrm{mM})$ were determined and the uptake of cephalexin measured in the variants at a concentration affording $70 \%$ inhibition of cephalexin in the wild-type transfected cells (Table 5). No significant differences were observed between any of the variants in terms of cephalexin inhibition, the exception being a VAC inhibition in F28Y cells. However, standard deviations of the assays were relatively high and thus, the sensitivity of this assay is relatively low.

\section{Subcellular expression of WT and F28Y in transiently transfected HEK 293 cells}

The subcellular localization of PEPT1 in HEK 293 cells transiently transfected with WT and F28Y is shown in figure 5. For both WT and F28Y, the PEPT1 protein was primarily localized in the cell membrane and in adjacent vesicles. No staining was observed in mock transfected cells or in preparations without primary antibody (data not shown). Therefore, subcellular localization of the PEPT1 protein in HEK 293 cells appears to be similar for WT and F28Y.

\section{Measurement of allelic expression imbalance on PEPT1 in human small intestines}

To detect any cis-acting polymorphisms affecting mRNA levels, we measured allelic ratios in genomic DNA and mRNA of human intestinal samples, using a nonsynonymous marker SNP in exon 17 (T1347T). Of 56 samples genotyped, 24 were heterozygous for $T 1347 T$ and eligible for allele-specific mRNA analysis using SNaPshot (Figure 6 panel A). Because the assay was unusually precise, at least in part owing to the robust expression of PEPT1 in the small intestinal samples, a majority showed allelic mRNA ratios significantly different from those in genomic DNA, indicating the presence of some cis-acting factor. However, only 7 samples showed deviations from unity of $20 \%$ to maximally $30 \%$. This result documents the presence of allelic expression imbalance, but the differences are relatively small. We cannot exclude the possibility that some differences between alleles could have been generated by differential decay after dissection and storage. However, a majority of samples showed differences in allelic mRNA ratios deviating less than $10 \%$ for the expected unity (after correction for the genomic DNA ratios). Moreover, we use 
JPET \#94615

a gene-specific primer for the cDNA synthesis with close proximity to the marker SNP, so that some mRNA degradation can be accommodated. In each sample, one allele serves as the control for the other, making this analysis more precise than is possible for absolute mRNA measurements.

\section{Measurements of the splice variant PEPT1-RF.}

We determined the relative levels of WT PEPT1 and PEPT1-RF mRNA in 32 intestinal samples with the use of real-time RT-PCR, using exon-specific primers. Between 2 and $44 \%$ of the total PEPT1-related mRNA was attributable to PEPT1-RF, demonstrating significant variability among individuals (Figure 6 panel B). We did not attempt to determine the overall amount of PEPT1 mRNA because these samples were collected under varying conditions, so that some degradation is unavoidable. We cannot exclude the possibility that the two splice forms decay differentially after the tissue has been dissected, but the large variations argue against this as a likely explanation of the results. 


\section{DISCUSSION}

This study combines a large sequencing analysis of PEPT1 in 247 ethnically diverse subjects, with an experimental approach to assess cis-acting polymorphisms affecting gene regulation and mRNA processing. Allelic diversity and haplotype distributions were determined, and nonsynonymous SNPs evaluated for functional effects, extending an earlier study (Zhang et al., 2004). Moreover, we determined allelic expression imbalance and alternative splicing to regulatory variants of PEPT1 in human intestinal samples. The results demonstrate a lack of functional genetic defects, with only rare variants affecting protein function or gene regulation. The significance of variable splicing remains to be determined. This study validates the use of PEPT1 as an entry port for oral bioavailability for peptidomimetic drugs, with genetic variability in intestinal transport activity expected to be limited.

Because we had access to a large sequence database, the results were evaluated in terms of population dynamics and evolution, using the ratio of synonymous over non-synonymous SNPs as an indicator. This assumes that nonsynonymous substitution may be deleterious and selected against. Nucleotide diversity, $\pi$, was consistently lower than $\theta$ yielding negative Tajima's D-values similar to those observed previously (Cargill et al., 1999; Halushka et al., 1999; Stephens et al., 2001), except for Hispanics, possibly due to small sample size. This finding is consistent with selection of one specific allele over alternate alleles. Ratios of $\pi_{\text {non-synonymous }}$ over $\pi_{\text {synonymous, }}$ overall $<1$, are similar to those reported earlier (Cargill et al., 1999; Halushka et al., 1999) in studies of genetic variation in over 75 genes. Ratios over 1 indicate that there is a selection for a function of a given gene, which does not seem to be the case for PEPT1.

Overall, our results confirm earlier findings (Zhang et al., 2004) observed in a smaller sample set. Most coding region SNPs were observed in both sample sets (Zhang et al., 2004), with some exceptions. Most nonsynonymous SNPs occur in poorly conserved regions, and the majority of protein variants tested showed no altered functionality. Only two rare SNPs lead to a functional change: PEPT1-P586L studied earlier (Zhang et al., 2004) and PEPT1-F28Y characterized here. Whereas P586L shows decreased transport capacity due to reduced protein 


\section{JPET \#94615}

expression, F28Y has similar expression levels as wild-type but altered affinity (i.e., higher $\mathrm{K}_{\mathrm{m}}$ value for dipeptide transport).

In addition to coding sequence analysis performed in the earlier study (Zhang et al., 2004), we analyzed adjoining intronic regions, and a portion of the deduced upstream promoter region. Approximately $6 \%$ of the mutations occur in introns and could potentially modulate consensus splice-site signals; such mutations have the potential to cause exon skipping (Aretz et al., 2004). The highest allele frequency (30\%) was observed for one SNP in the intronic region adjoining exon 13. PEPT1 has 23 exons while the splice variant, PEPT1-RF, has 6. PEPT1-RF shares 3 exons completely and 2 exons partially with PEPT1 (Urtti et al., 2001). No polymorphisms were observed in regions surrounding the splice sites that would predict genetic differences in PEPT1-RF formation.

In vitro uptake studies in transiently transfected $\mathrm{CHO}$ and $\mathrm{Cos} 7$ cells were performed for phenotypic characterization of non-synonymous PEPT1 variants. Of 8 variants investigated, one (F28Y) showed significantly reduced cephalexin uptake compared to wild type. Detailed kinetic studies in HEK 293 cells demonstrated that the $K_{m}$ and $V_{\max }$ values for Gly-Sar uptake by variants S117N and G419A were similar to values obtained for WT PEPT1. This confirms the earlier study (Zhang et al., 2004) where Gly-Sar uptake was measured in transiently transfected HeLa cells, showing that S117N, V122M, G419A and T451N had similar Gly-Sar uptake compared to wildtype PEPT1.

For F28Y, altered transport of Gly-Sar and cephalexin was observed in various transfected mammalian cells. PEPT1 transport is partly driven by the proton-gradient across intestinal epithelial cells. The pH-dependence for Gly-Sar transport via WT, S117N, and G419A reported here is similar to that obtained in oocytes transfected with PEPT1, and in Caco-2 cells where functional NHE3 activity was suppressed with inhibitors (Kennedy et al., 2002). This indicates that both $\mathrm{S} 117 \mathrm{~N}$ and $\mathrm{G} 419 \mathrm{~A}$ retain substrate transport activity with unchanged $\mathrm{pH}$ dependence. In contrast, F28Y showed a pH-profile similar to that previously observed in Caco-2 cells with functional NHE3 activity and the presence of the regulatory factor PEPT1-RF (Saito et al., 1997; Kennedy et al., 2002). Altered $\mathrm{pH}$ dependence of F28Y could be related to the 
JPET \#94615

phenylalanine to tyrosine substitution, which may affect proton binding to His57, shown to be important for proton binding (Fei et al., 1997; Fei et al., 1998). Previous studies have shown that tyrosine residues in positions 54, 65, and 167 appear to be involved in proton binding (Yeung et al., 1998; Chen et al., 2000). For position 282 a substitution of arginine to lysine did not alter PEPT1 transport activity whereas substitution to glutamine resulted in the uncoupling of proton dependence (Kulkarni et al., 2003). Since the 3D structure of PEPT1 is currently unknown, no one knows how these residues interact. Sequence comparison across different species showed that the surounding F28Y region (Urtti et al., 2001; Zhang et al., 2004) is highly conserved across species. The only other PEPT1 variant in a highly conserved region is V21I, showing no functional defect. However, in contrast to Phe28, which was conserved across all species, replacement of valine with isoleucine occurs in gallus (cf. table 6). Lee et al. (Lee et al., 1999) proposed a theoretical model for PEPT1. The model, based on pair-wise calculations and amphipathicity, proposed that TMDs with highest amphipathicity faced a central channel. Using this computational model, they identified amino acids that were likely to alter PEPT1 transport function. Three out of four mutations implicated by this model were indeed defective in Gly-Sar transport. None of the natural PEPT1 variants identified here are in regions proposed to be relevant for transport function, consistent with a lack of functional effect of these natural variants.

Whereas most previous studies on human genetic variability have focused on coding regions, it is likely that more genetic variants affect mRNA levels by multiple mechanisms. Thus, synonymous SNPs, and SNPs in intronic or regulatory regions, could affect PEPT1 expression or splicing, and hence PEPT1 activity. We have addressed this possibility by measuring allelic expression imbalance, with a marker SNP in exon 17 in relevant target tissues, in this case small intestines. We obtained tissue samples from various locations (duodenum, jejunum, ileum), but did not attempt to analyze these separately, because we were limited in sample number. Still, the 24 samples analyzed permit a survey of 48 alleles, sufficient to detect any functional polymorphism with $\sim 5 \%$ allele frequency. Only 7 samples displayed allelic mRNA expression imbalance with $20-30 \%$ deviations from unity, and indicate the presence of frequent cis-acting polymorphisms with limited effect on relative mRNA levels. One can use allelic mRNA ratios as a 


\section{JPET \#94615}

phenotype for identifying any polymorphisms in the PEPT1 gene locus (including potential regulatory polymorphisms that could reside far upstream of the initiation site). However, in view of the relatively small expression imbalance, we judged it to be unlikely that any functional polymorphism we might identify would have substantial effect on interindividual variability in PEPT1 intestinal activity. Therefore, we did not pursue the functional genetic variants responsible for the allelic expression imbalance.

Alternative splicing leads to the formation of PEPT1-RF that modulates transport activity of PEPT1 (Saito et al., 1997). Alternative splicing occurs at exon 3 and yields a product that shares several exons with the wild-type PEPT1 (Urtti et al., 2001). We determined the extent of PEPT1-RF mRNA formation in 32 intestinal samples, showing a variance of $2-44 \%$ of total PEPT1 mRNA activity. Because the marker SNP we selected for the allelic expression imbalance assay resides in exon 17, not present in PEPT1-RF, we cannot determine whether variable splicing is mediated by cis-acting factors, or in trans. Our sequence analysis failed to reveal any sufficiently frequent polymorphisms in the relevant splice region, arguing against the presence of cis-acting factors. Moreover, we cannot determine whether PEPT1/PEPT-RF mRNA ratios are constant within the same individual or fluctuate with nutrition, age, disease, etc. Before these questions are addressed, in vitro studies need to be performed to determine whether PEPT1-RF has the potential to significantly affect PEPT1 transport at the levels found in the intestinal samples.

In conclusion, characterization of the non-synonymous SNPs reveals an absence of functional SNPs of sufficient frequency to exert significant impact on bioavailability of PEPT1 substrates. Similarly, any cis-acting factors affecting mRNA expression and processing are unlikely to have strong impact on intestinal PEPT1 transport. Possibly, genetic factors could introduce some systematic variability for drugs critically dependent on PEPT1 activity for intestinal absorption. However, other factors acting on PEPT1 transport activity are more likely to cause interindividual variability, recently studied with VAC in human subjects (Phan et al., 2003). Alternative splicing cannot as yet be ruled out as a clinically relevant variable. Overall, however, 


\section{JPET \#94615}

PEPT1 displays remarkable low genetic variability. This finding is important for drug therapy with peptoid drugs, and for exploiting PEPT1 in prodrug design for improved bioavailability. 


\section{ACKNOWLEDGMENT}

We thank Dr. Danxin Wang for discussion and technical support, and Helle Bach Sondergaard and Susanne Sondergaard for technical assistance. The Pharmacogenetics of Membrane Transporters Investigators are: Leslie Z. Benet, Claire M. Brett, Esteban G. Burchard, Richard Castro, Melanie de la Cruz, Robert H. Edwards, Kathleen L. Giacomini, Jane Gitschier, Charles E. Glatt, Chesi Ho, Deanna L. Kroetz, Emil T. Lin, Victor I. Reus, Neil Risch, Wolfgang Sadee, Michael Salazar, Catherine Schaefer, Kelly Taylor, Cindy Tran, Christopher Vulpe, Ernest M. Wright, and Hee Jae Yoon." 


\section{REFERENCES}

Aretz S, Uhlhaas S, Sun Y, Pagenstecher C, Mangold E, Caspari R, Moslein G, Schulmann K, Propping P and Friedl W (2004) Familial adenomatous polyposis: aberrant splicing due to missense or silent mutations in the APC gene. Hum Mutat 24:370-380.

Bravo SA, Nielsen CU, Amstrup J, Frokjaer S and Brodin B (2004) Epidermal growth factor decreases PEPT2 transport capacity and expression in the rat kidney proximal tubule cell line SKPT0193 cl.2. Am J Physiol Renal Physiol 286:F385-393.

Cargill M, Altshuler D, Ireland J, Sklar P, Ardlie K, Patil N, Shaw N, Lane CR, Lim EP, Kalyanaraman N, Nemesh J, Ziaugra L, Friedland L, Rolfe A, Warrington J, Lipshutz R, Daley GQ and Lander ES (1999) Characterization of single-nucleotide polymorphisms in coding regions of human genes. Nat Genet 22:231-238.

Chen XZ, Steel A and Hediger MA (2000) Functional roles of histidine and tyrosine residues in the $\mathrm{H}(+)$-peptide transporter PepT1. Biochem Biophys Res Commun 272:726-730.

Covitz KM, Amidon GL and Sadee W (1996) Human dipeptide transporter, hPEPT1, stably transfected into Chinese hamster ovary cells. Pharm Res 13:1631-1634.

Covitz KM, Amidon GL and Sadee W (1998) Membrane topology of the human dipeptide transporter, hPEPT1, determined by epitope insertions. Biochemistry 37:15214-15221.

Dai Z and Sadee W (2005) Pharmacogenetics/genomics and personalized medicine. Hum Mol Genet in press.

Fei YJ, Liu JC, Fujita T, Liang R, Ganapathy V and Leibach FH (1998) Identification of a potential substrate binding domain in the mammalian peptide transporters PEPT1 and PEPT2 using PEPT1-PEPT2 and PEPT2-PEPT1 chimeras. Biochem Biophys Res Commun 246:39-44.

Fei YJ, Liu W, Prasad PD, Kekuda R, Oblak TG, Ganapathy V and Leibach FH (1997) Identification of the histidyl residue obligatory for the catalytic activity of the human H+/peptide cotransporters PEPT1 and PEPT2. Biochemistry 36:452-460. 


\section{JPET \#94615}

Ganapathy ME, Brandsch M, Prasad PD, Ganapathy V and Leibach FH (1995) Differential recognition of beta -lactam antibiotics by intestinal and renal peptide transporters, PEPT 1 and PEPT 2. J Biol Chem 270:25672-25677.

Halushka MK, Fan JB, Bentley K, Hsie L, Shen N, Weder A, Cooper R, Lipshutz R and Chakravarti A (1999) Patterns of single-nucleotide polymorphisms in candidate genes for blood-pressure homeostasis. Nat Genet 22:239-247.

Han H, de Vrueh RL, Rhie JK, Covitz KM, Smith PL, Lee CP, Oh DM, Sadee W and Amidon GL (1998) 5'-Amino acid esters of antiviral nucleosides, acyclovir, and AZT are absorbed by the intestinal PEPT1 peptide transporter. Pharm Res 15:1154-1159.

Hoffmeyer S, Burk O, von Richter O, Arnold HP, Brockmoller J, Johne A, Cascorbi I, Gerloff T, Roots I, Eichelbaum M and Brinkmann U (2000) Functional polymorphisms of the human multidrug-resistance gene: multiple sequence variations and correlation of one allele with P-glycoprotein expression and activity in vivo. Proc Natl Acad Sci U S A 97:3473-3478.

Johnson AD, Wang D and Sadee W (2005) Polymorphisms affecting gene regulation and mRNA processing: broad implications for pharmacogenetics. Pharmacol Ther 106:19-38.

Kennedy DJ, Leibach FH, Ganapathy V and Thwaites DT (2002) Optimal absorptive transport of the dipeptide glycylsarcosine is dependent on functional $\mathrm{Na}+\mathrm{H}+$ exchange activity. Pflugers Arch 445:139-146.

Kulkarni AA, Haworth IS, Uchiyama T and Lee VH (2003) Analysis of transmembrane segment 7 of the dipeptide transporter hPepT1 by cysteine-scanning mutagenesis. J Biol Chem 278:51833-51840.

Lee VH, Chu C, Mahlin ED, Basu SK, Ann DK, Bolger MB, Haworth IS, Yeung AK, Wu SK, Hamm-Alvarez S and Okamoto CT (1999) Biopharmaceutics of transmucosal peptide and protein drug administration: role of transport mechanisms with a focus on the involvement of PepT1. J Control Release 62:129-140.

Licinio J and Wong ML (2002) Pharmacogenomics: The search for individualized therapies. WILEY-VCH Verlag GmbH, Weinheim. 
JPET \#94615

Miller SA, Dykes DD and Polesky HF (1988) A simple salting out procedure for extracting DNA from human nucleated cells. Nucleic Acids Res 16:1215.

Modrek B and Lee C (2002) A genomic view of alternative splicing. Nat Genet 30:13-19.

Nielsen CU, Amstrup J, Steffansen B, Frokjaer S and Brodin B (2001) Epidermal growth factor inhibits glycylsarcosine transport and hPepT1 expression in a human intestinal cell line. Am J Physiol Gastrointest Liver Physiol 281:G191-199.

Phan DD, Chin-Hong P, Lin ET, Anderle P, Sadee W and Guglielmo BJ (2003) Intra- and interindividual variabilities of valacyclovir oral bioavailability and effect of coadministration of an hPEPT1 inhibitor. Antimicrob Agents Chemother 47:2351-2353.

Pinsonneault J, Nielsen CU and Sadee W (2004) Genetic variants of the human $\mathrm{H}+$ /dipeptide transporter PEPT2: analysis of haplotype functions. J Pharmacol Exp Ther 311:10881096.

Rockman MV and Wray GA (2002) Abundant raw material for cis-regulatory evolution in humans. Mol Biol Evol 19:1991-2004.

Saito H, Motohashi H, Mukai M and Inui K (1997) Cloning and characterization of a pH-sensing regulatory factor that modulates transport activity of the human $\mathrm{H}+$ /peptide cotransporter, PEPT1. Biochem Biophys Res Commun 237:577-582.

Stephens JC, Schneider JA, Tanguay DA, Choi J, Acharya T, Stanley SE, Jiang R, Messer CJ, Chew A, Han JH, Duan J, Carr JL, Lee MS, Koshy B, Kumar AM, Zhang G, Newell WR, Windemuth A, Xu C, Kalbfleisch TS, Shaner SL, Arnold K, Schulz V, Drysdale CM, Nandabalan K, Judson RS, Ruano G and Vovis GF (2001) Haplotype variation and linkage disequilibrium in 313 human genes. Science 293:489-493.

Tajima F (1989) Statistical method for testing the neutral mutation hypothesis by DNA polymorphism. Genetics 123:585-595.

Urtti A, Johns SJ and Sadee W (2001) Genomic structure of proton-coupled oligopeptide transporter hPEPT1 and pH-sensing regulatory splice variant. AAPS PharmSci 3:E6. 
JPET \#94615

Wang D, Johnson AD, Papp A, Kroetz DL and Sadee W (2005) Multidrug Resistance Polypeptide 1 (MDR1, ABCB1) variant 3435C>T affects mRNA atability. Pharmacogen Genomics in press.

Yan H, Yuan W, Velculescu VE, Vogelstein B and Kinzler KW (2002) Allelic variation in human gene expression. Science 297:1143.

Yeung AK, Basu SK, Wu SK, Chu C, Okamoto CT, Hamm-Alvarez SF, von Grafenstein H, Shen WC, Kim KJ, Bolger MB, Haworth IS, Ann DK and Lee VH (1998) Molecular identification of a role for tyrosine 167 in the function of the human intestinal proton- coupled dipeptide transporter (hPepT1). Biochem Biophys Res Commun 250:103-107.

Zhang EY, Fu DJ, Pak YA, Stewart T, Mukhopadhyay N, Wrighton SA and Hillgren KM (2004) Genetic Polymorphisms in Human Proton-Dependent Dipeptide Transporter PEPT1: Implications for the Functional Role of Pro586. J Pharmacol Exp Ther 310: 437-445. 


\section{FOOTNOTES}

a) Financial support. This work was supported in part by NIH General Medical Sciences, grant GM61390, Plasma Membrane Transporter Group at UCSF, National Institute on Drug Abuse, grant DA018744, and The Danish University of Pharmaceutical Sciences.

b) Reprint requests

Wolfgang Sadée

Department of Pharmacology

OSU Program in Pharmacogenomics

333 W. 10th Avenue

Columbus, $\mathrm{OH} 43210$

Phone: (614) 292-1597

Fax: (614) 292-7232

Email: sadee-1@medctr.osu.edu 


\section{LEGENDS FOR FIGURES}

Figure 1: Topographical prediction of transmembrane domains of PEPT1. Image shown was generated using TOPO, a transmembrane protein display program. Non-synonymous SNPs causing amino acid changes are shown in black, and synonymous SNPs in gray.

Figure 2: Uptake of $1.44 \mu \mathrm{M}$ cephalexin at $37^{\circ} \mathrm{C}$ for $60 \mathrm{~min}, \mathrm{pH} 6$ in transiently transfected $\mathrm{CHO}$ and Cos7 cells $(n=3$, mean \pm SDs).

Figure 3: Uptake rate of $\left[{ }^{14} \mathrm{C}\right]$ Gly-Sar as a function of extracellular [Gly-Sar]. HEK 293 cells transiently transfected with PEPT1 variants were incubated with $\left[{ }^{14} \mathrm{C}\right] \mathrm{Gly}-\mathrm{Sar}\left(1,0 \mu \mathrm{Ci} \mathrm{mL}{ }^{-1}\right)$ for 15 min. $(\bullet)$ at $\mathrm{pH}$ 6: WT, $(\Delta)$ : G419A, (口): S117N and (०): F28Y. Cells were washed 4 times in icecold HBSS and solubilized. Radioactivity and protein amounts were determined and uptake was calculated. Each bar represents mean \pm SE of $5-6$ individual transfections. The lines represent the calculated fits to the Michaelis-Menten equation (eq. 1).

Figure 4: Uptake rate of $20 \mu \mathrm{M}$ Gly-Sar as a function of extracellular pH. HEK 293 cells transiently transfected with PEPT1 variants were incubated with $\left[{ }^{14} \mathrm{C}\right] \mathrm{Gly}-\mathrm{Sar}(1.0 \mu \mathrm{Ci} / \mathrm{ml})$ for 5 min. $(\bullet)$ : WT, $(\Delta)$ : G419A, (口): S117N, (०): F28Y. Cells were washed 4 times in ice-cold HBSS and solubilised. Radioactivity and protein amounts were determined and uptake was calculated. Each bar represents mean \pm SE of 5-6 individual transfections.

Figure 5: Immuno-localization of PEPT1 by anti-PEPT1 immunostaining. HEK 293 transiently transfected with WT (A) or F28Y (B) were fixed in 3\% formaldehyde and permeabilized in $0.1 \%$ Triton $\mathrm{x}-100$. Cells treated with anti-PEPT1 antibody followed by labeling with a secondary Alexa 488-conjugated goat anti-rabbit (green fluorescence). Vertical sections through HEK 293 cells labeled with anti-PEPT1/Alexa 488 goat-anti-rabbit antibodies and counterstained with propidium iodide to visualize nuclei, where PEPT1-staining is green and nuclei is red. No staining was 


\section{JPET \#94615}

observed in mock transfected cells or in preparations without primary antibody. The red bar corresponds to $10 \mu \mathrm{M}$. The images are representative of three individual preparations.

Figure 6: PEPT1 mRNA expression profiles in small intestinal tissue samples obtained from biopsies. A) Allele-specific expression ratios of 21 small intestinal samples heterozygous for a synonymous SNP in exon 17. Ratios are expressed as major allele over minor allele (T/C) and have been normalized to DNA, which was assumed to have equal number of alleles, i.e., a ratio of 1.0. ( $n=6$ replicates for SB02 through SB12, and $n=3$ for all other samples). Samples labeled with an asterisk $\left(^{*}\right)$ have allelic mRNA ratios that differ statistically from unity. B) Relative abundances of full length and alternatively spliced (RF) mRNA transcripts of PEPT1. Values are averages of 2 measurements. Amounts of the RF splice variant range from $2 \%$ to $44 \%$ of the total transcript. 


\section{JPET\#94615}

Table1: Genotyping of exons and adjoining intronic regions, and upstream promoter of PEPT1.

AA: African American, CA: Caucasian, AS: Asians (Japanese, Chinese, SE Asians), HI: Hispanics, PI: Pacific Islander

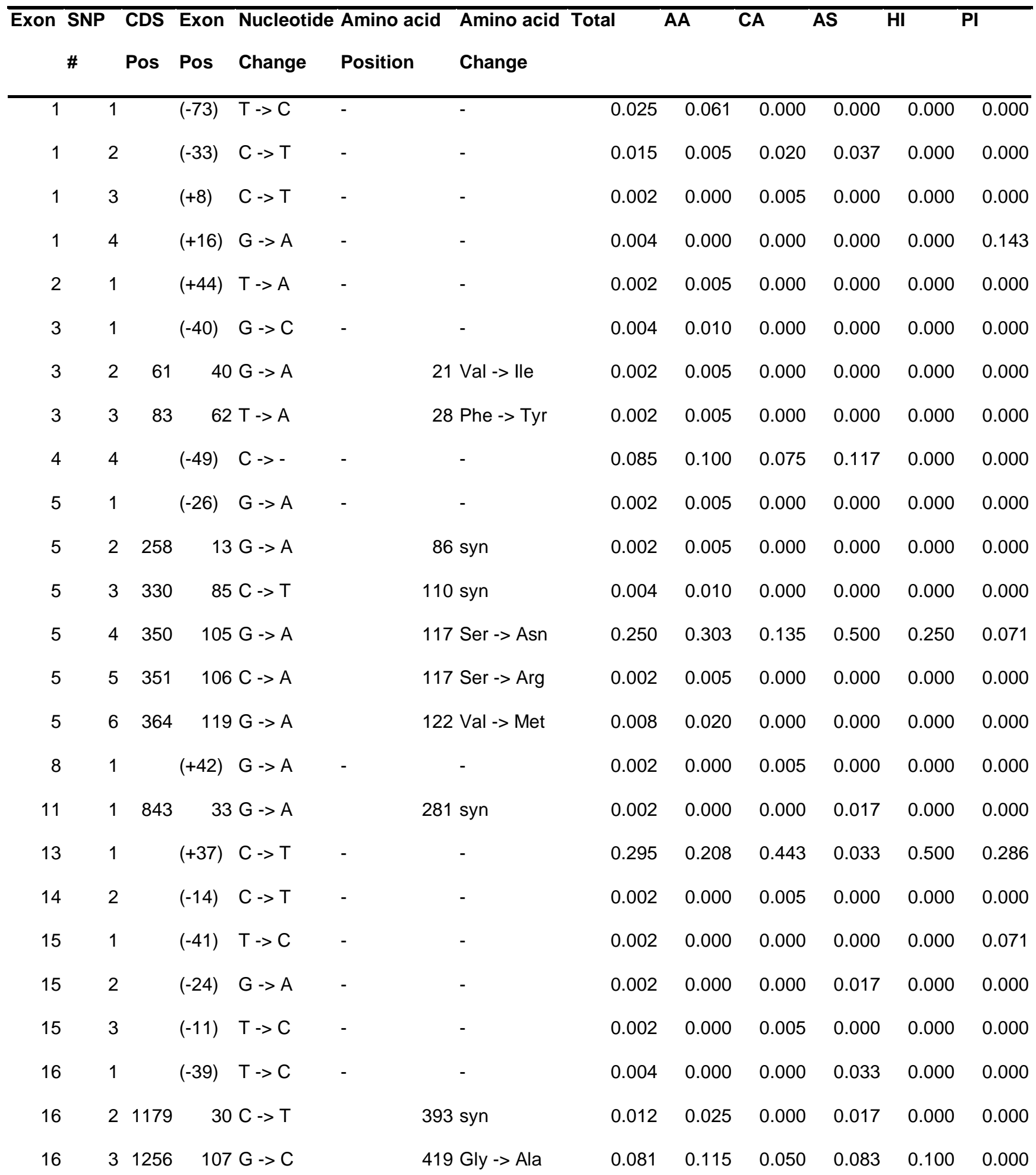




\section{JPET\#94615}

\begin{tabular}{|c|c|c|c|c|c|c|c|c|c|c|}
\hline 17 & 11347 & $78 \mathrm{~T}->\mathrm{C}$ & & 449 syn & 0.138 & 0.125 & 0.120 & 0.117 & 0.350 & 0.357 \\
\hline 17 & 21348 & $79 G->A$ & & $450 \mathrm{Val}->\mathrm{lle}$ & 0.014 & 0.020 & 0.000 & 0.017 & 0.000 & 0.143 \\
\hline 17 & 31352 & $83 \mathrm{C} \rightarrow \mathrm{A}$ & & $451 \mathrm{Thr}->$ Asn & 0.012 & 0.005 & 0.020 & 0.017 & 0.000 & 0.000 \\
\hline 18 & 1 & $(-55) \quad C->A$ & - & - & 0.077 & 0.106 & 0.050 & 0.100 & 0.050 & 0.000 \\
\hline 18 & 21446 & $30 A->G$ & & 482 syn & 0.006 & 0.015 & 0.000 & 0.000 & 0.000 & 0.000 \\
\hline 18 & 3 & $(+3) \quad A->G$ & - & - & 0.014 & 0.005 & 0.025 & 0.000 & 0.050 & 0.000 \\
\hline 18 & 4 & $(+39) \quad C->T$ & - & - & 0.024 & 0.060 & 0.000 & 0.000 & 0.000 & 0.000 \\
\hline 19 & 11527 & $61 \mathrm{C}->\mathrm{T}$ & & 509 syn & 0.094 & 0.180 & 0.045 & 0.000 & 0.050 & 0.000 \\
\hline 20 & 2 & $(-54) \quad A->G$ & - & - & 0.004 & 0.010 & 0.000 & 0.000 & 0.000 & 0.000 \\
\hline 20 & 31609 & $35 \mathrm{C} \rightarrow \mathrm{T}$ & & 537 Pro $->$ Ser & 0.002 & 0.005 & 0.000 & 0.000 & 0.000 & 0.000 \\
\hline 20 & 4 & $(+12) \quad G->A$ & - & - & 0.012 & 0.000 & 0.000 & 0.107 & 0.000 & 0.000 \\
\hline 21 & 1 & $(-36) \quad A->G$ & - & - & 0.004 & 0.000 & 0.000 & 0.017 & 0.050 & 0.000 \\
\hline 22 & 11848 & $21 G->A$ & & 616 syn & 0.002 & 0.000 & 0.005 & 0.000 & 0.000 & 0.000 \\
\hline
\end{tabular}


JPET Fast Forward. Published on October 28, 2005 as DOI: 10.1124/jpet.105.094615

This article has not been copyedited and formatted. The final version may differ from this version.

\section{JPET\#94615}

Table 2: Estimates of the neutral parameter $\theta$, nucleotide diversity $\pi$, and Tajima's $D$.

\begin{tabular}{|c|c|c|c|c|c|c|c|}
\hline Population & SNP type & $\begin{array}{l}\text { Base pairs } \\
\text { screened }\end{array}$ & $\mathrm{n}^{\mathrm{a}}$ & No. variable sites ${ }^{b}$ & $\theta(\mathrm{SD}) \times 10^{4}$ & $\pi(\mathrm{SD}) \times 10^{4}$ & $\bar{D}$ \\
\hline \multirow[t]{6}{*}{$\bar{A} I^{c}$} & Total & 4501 & 494 & 37 & $12.13(3.04)$ & $4.09(2.60)$ & -2.54 \\
\hline & Non-Coding & 2374 & 494 & 20 & $12.43(3.64)$ & $3.27(2.64)$ & -1.99 \\
\hline & Coding & 2127 & 494 & 17 & $11.79(3.63)$ & $5.02(3.68)$ & -1.41 \\
\hline & Intron-Exon Boundary & 253 & 494 & 2 & $11.66(8.54)$ & $1.26(4.12)$ & -0.53 \\
\hline & Synonymous & 473.33 & 494 & 8 & $24.93(10.00)$ & $9.74(9.49)$ & -0.93 \\
\hline & Non-synonymous & 1653.67 & 494 & 9 & $8.03(3.08)$ & $3.66(3.23)$ & -0.9 \\
\hline \multicolumn{8}{|c|}{ African American } \\
\hline & Total & 4501 & 200 & 25 & $9.46(2.80)$ & $4.82(2.97)$ & -1.68 \\
\hline & Non-Coding & 2374 & 200 & 10 & $7.17(2.75)$ & $3.35(2.70)$ & -1.06 \\
\hline & Coding & 2127 & 200 & 15 & 12.01(4.06) & $6.46(4.43)$ & -1.18 \\
\hline & Intron-Exon Boundary & 253 & 200 & 1 & $6.73(6.89)$ & $0.40(2.30)$ & -0.39 \\
\hline & Synonymous & 473.33 & 200 & 6 & $21.58(9.99)$ & $13.20(11.53)$ & -0.56 \\
\hline & Non-synonymous & 1653.67 & 200 & 9 & $9.27(3.69)$ & $4.53(3.72)$ & -0.95 \\
\hline \multicolumn{8}{|l|}{ Caucasian } \\
\hline & Total & 4501 & 200 & 14 & $5.30(1.83)$ & $3.01(2.07)$ & -1.05 \\
\hline & Non-Coding & 2374 & 200 & 8 & $5.74(2.38)$ & $2.86(2.43)$ & -0.87 \\
\hline & Coding & 2127 & 200 & 6 & $4.80(2.22)$ & $3.18(2.71)$ & -0.49 \\
\hline & Intron-Exon Boundary & 253 & 200 & 2 & $13.46(9.96)$ & $2.30(5.64)$ & -0.57 \\
\hline & Synonymous & 473.33 & 200 & 3 & $10.79(6.66)$ & $6.50(7.47)$ & -0.36 \\
\hline & Non-synonymous & 1653.67 & 200 & 3 & $3.09(1.91)$ & $2.24(2.38)$ & -0.25 \\
\hline \multicolumn{8}{|l|}{ Asian } \\
\hline & Total & 4501 & 60 & 14 & $6.67(2.55)$ & $3.59(2.39)$ & -1.37 \\
\hline & Non-Coding & 2374 & 60 & 7 & $6.32(2.95)$ & $2.57(2.29)$ & -1.16 \\
\hline & Coding & 2127 & 60 & 7 & $7.06(3.29)$ & $4.73(3.58)$ & -0.65 \\
\hline & Intron-Exon Boundary & 253 & 60 & 0 & $0.00(0.00)$ & $0.00(0.00)$ & $n / a$ \\
\hline & Synonymous & 473.33 & 60 & 3 & $13.59(8.68)$ & $5.84(7.09)$ & -0.64 \\
\hline & Non-synonymous & 1653.67 & 60 & 4 & $5.19(2.96)$ & $4.42(3.70)$ & -0.2 \\
\hline \multicolumn{8}{|l|}{ Latino } \\
\hline & Total & 4501 & 20 & 8 & $5.01(2.51)$ & $4.42(2.91)$ & -0.32 \\
\hline & Non-Coding & 2374 & 20 & 4 & $4.75(2.91)$ & $3.48(2.90)$ & -0.48 \\
\hline
\end{tabular}


JPET Fast Forward. Published on October 28, 2005 as DOI: 10.1124/jpet.105.094615

This article has not been copyedited and formatted. The final version may differ from this version.

JPET\#94615

\begin{tabular}{|l|l|l|l|l|l|l|l|}
\hline & Coding & 2127 & 20 & 4 & $5.30(3.25)$ & $5.47(4.11)$ & 0.06 \\
\hline & Intron-Exon Boundary & 253 & 20 & 1 & $11.14(11.83)$ & $3.95(7.84)$ & -0.46 \\
\hline & Synonymous & 473.33 & 20 & 2 & $11.91(9.43)$ & $12.23(11.50)$ & 0.03 \\
\hline & Non-synonymous & 1653.67 & 20 & 2 & $3.41(2.70)$ & $3.53(3.31)$ & 0.04 \\
\hline Pacific Islander & & & & & $4.19(2.38)$ & $3.88(2.69)$ & -0.19 \\
\hline & Total & 4501 & 14 & 6 & $3.97(2.78)$ & $3.56(3.01)$ & -0.18 \\
\hline & Non-Coding & 2374 & 14 & 3 & $4.44(3.10)$ & $4.24(3.51)$ & -0.08 \\
\hline & Coding & 2127 & 14 & 3 & $0.00(0.00)$ & $0.00(0.00)$ & $n / a$ \\
\hline & Intron-Exon Boundary & 253 & 14 & 0 & $6.64(7.14)$ & $10.45(10.64)$ & 0.47 \\
\hline & Synonymous & 473.33 & 14 & 1 & $3.80(3.08)$ & $2.46(2.70)$ & -0.46 \\
\hline
\end{tabular}

${ }^{a}$ Number of chromosomes, ${ }^{b}$ deletions and insertions were excluded from these statistics, ${ }^{c}$ entire sample. 
Table 3: Haplotypes of PEPT1 with a frequency of $1 \%$ or more. Each letter represents a single nucleotide polymorphism (SNP). Thirty-eight SNPs were included in the analysis, listed in the order presented in Table 1. Haplotypes were determined using the PHASE algorithm.

\begin{tabular}{|c|c|c|c|c|c|c|c|}
\hline \# HT & Haplotype & \% samples & $\%$ AA & $\% \mathbf{C A}$ & $\%$ AS & $\%$ LA & $\%$ PA \\
\hline$\overline{1}$ & TCCGTGGTCGGCGCGGGCCTGTTCGTGCCAACCACGAG & $\overline{24.6}$ & 16.9 & 30.6 & $\overline{32.3}$ & 15 & $\overline{28.6}$ \\
\hline 2 & TCCGTGGTCGGCGCGGGTCTGTTCGTGCCAACCACGAG & 19.7 & 11.8 & 33.1 & 1.7 & 22.5 & 14.3 \\
\hline 3 & TCCGTGGTCGGCACGGGCCTGTTCGTGCCAACCACGAG & 10.3 & 10.3 & 8 & 16 & 17.5 & 7.1 \\
\hline 4 & TCCGTGGTCGGCGCGGGCCTGTTCGTGCCAACTACGAG & 4.7 & 9.2 & 2.5 & 0 & 0 & $c$ \\
\hline 5 & TCCGTGGTCGGCGCGGGTCTGTTCGCGCCAACCACGAG & 4.6 & 1.1 & 6.7 & 0 & 25 & 14.3 \\
\hline 6 & TCCGTGGTCGGCGCGGGCCTGTTCCTGCAAACCACGAG & 3 & 4.8 & 2.5 & 0 & 0 & 0 \\
\hline 7 & TCCGTGGT-GGCACGGGCCTGTTCGTGCCAACCACGAG & 2.8 & 4.2 & 1.6 & 3.5 & 0 & ( \\
\hline 8 & TCCGTGGTCGGCGCGGGCCTGTTCGCGCCAACCACGAG & 2.2 & 2.5 & 1.5 & 2.8 & 0 & 7.1 \\
\hline 9 & TCCGTGGTCGGCACGGGTCTGTTCGTGCCAACCACGAG & 2.1 & 4.7 & 0 & 1.7 & 0 & u \\
\hline 10 & TCCGTGGT-GGCGCGGGCCTGTTCGTGCCAACCACGAG & 1.3 & 0.8 & 2.4 & 0 & 0 & 0 \\
\hline 11 & TCCGTGGTCGGCGCGGGCCTGTTCGTGCCAATCACGAG & 1.2 & 3 & 0 & 0 & 0 & 0 \\
\hline 12 & TCCGTGGT- GGCACGGGCCTGTTCGTGCCAACTACGAG & 1.2 & 2.6 & 0.3 & 0 & 0 & 0 \\
\hline 13 & TCCGTGGTCGGCGCGGGCCTGTTCGCACCAACCACGAG & 1.2 & 1.5 & 0 & 1.7 & 0 & 12.9 \\
\hline 14 & TCCGTGGTCGGCGCGGGCCTGTTCCCGCAAACCACGAG & 1 & 1 & 1 & 0 & 5 & 0 \\
\hline 15 & CCCGTGGTCGGCGCGGGCCTGTTCGTGCCAACTACGAG & 1 & 2.5 & 0 & 0 & 0 & 0 \\
\hline 16 & TCCGTGGTCGGCACGGGCCTGTTCGTGCCAACCACAAG & 1 & 0 & 0 & 8.2 & 0 & 0 \\
\hline \multirow[t]{2}{*}{17} & TCCGTGGT-GGCACGGGCCTGTTCCTGCAAACCACGAG & 1 & 0.5 & 1 & 3.2 & 0 & 0 \\
\hline & Sum & 82.9 & 77.4 & 91.2 & 71.1 & 85 & 84.3 \\
\hline
\end{tabular}




\section{JPET\#94615}

Table 4: $K_{m}$ and $V_{\max }$ values (average $\pm S E, n=4$ ) obtained for Gly-Sar uptake rates by WT and F28Y calculated using the Michaelis-Menten equation (eq. 1).

\begin{tabular}{cccc}
\hline PEPT1 & $\mathrm{pH}$ & $\begin{array}{c}\mathrm{K}_{\mathrm{m}} \\
(\mathrm{mM})\end{array}$ & $\begin{array}{c}\mathrm{V}_{\max } \\
(\mathrm{nmol} / \mathrm{mg} \text { protein/min })\end{array}$ \\
\hline WT & 5.0 & $1.3 \pm 0.1$ & $3.2 \pm 0,5$ \\
WT & 6.0 & $1.6 \pm 0.1$ & $1.4 \pm 0.1$ \\
F28Y & 5.0 & $5.6 \pm 1$ & $4.7 \pm 0.2$ \\
F28Y & 6.0 & $2.7 \pm 0.2$ & $1.6 \pm 0.1$ \\
\hline
\end{tabular}




\section{JPET\#94615}

Table 5: Uptake [nmol/mg protein] of cephalexin at $37^{\circ} \mathrm{C}(\mathrm{pH} 6)$ in transiently transfected Cos7 cells in the presence of Leu-Ala $(0.69 \mathrm{mM}$, enalapril maleate $(13.0 \mathrm{mM})$ and L-Valacyclovir (VAC; $1.9 \mathrm{mM})(\mathrm{n}=3)$. Indicated in bold are significantly different uptake rate, i.e uptake rate in wild-type transfected cells compared to variant transfected cells.

\begin{tabular}{ccccc}
\hline Variant & Control & Leu-Ala & Enalapril & VAC \\
& Uptake (SD) & Uptake (SD) & Uptake (SD) & Uptake (SD) \\
\hline WT & $4.31(0.55)$ & $0.86(0.22)$ & $0.84(0.37)$ & $2.85(0.18)$ \\
V21I & $4.57(1.03)$ & $0.59(0.28)$ & $0.75(0.23)$ & $2.04(0.81)$ \\
Y28T & $\mathbf{2 . 1 4 ( 0 . 3 6 )}$ & $0.96(1.20)$ & $0.59(0.16)$ & $\mathbf{1 . 0 6}(0.81)$ \\
S117R & $4.57(2.00)$ & $0.79(0.03)$ & $1.21(0.29)$ & $2.17(0.28)$ \\
S117A & $5.07(2.63)$ & $1.03(0.14)$ & $1.10(0.26)$ & $1.53(0.88)$ \\
V122M & $3.46(1.20)$ & $0.78(0.25)$ & $0.93(0.20)$ & $1.51(0.58)$ \\
G451A & $4.04(1.48)$ & $0.69(0.20)$ & $1.67(0.58)$ & $2.25(1.22)$ \\
T451A & $4.93(3.68)$ & $1.18(0.44)$ & $1.72(0.38)$ & $1.47(1.01)$ \\
P537S & $3.62(1.51)$ & $0.74(0.26)$ & $0.30(0.08)$ & $1.70(0.57)$ \\
pcDNA3 & $\mathbf{0 . 3 5 ( 0 . 3 1 )}$ & $0.37(0.36)$ & $0.34(0.35)$ & $\mathbf{0 . 1 6 ( 0 . 2 9 )}$ \\
\hline
\end{tabular}




\section{JPET\#94615}

Table 6. Species comparison of sequence regions of the variants V21I and F28Y.

\begin{tabular}{lcc}
\hline \multicolumn{1}{c}{ Species } & \multicolumn{2}{c}{ Variants of PEPT1 } \\
(overall similarity) & V21I & F28Y \\
\hline Homo sapiens & FIVVNEF & CERFSYY \\
Oryctolagus (80\%) & FIVVNEF & CERFSYY \\
Rattus (82\%) & FIVVNEF & CERFSYY \\
Mus (82\%) & FIVVNEF & CERFSYY \\
Ovis aries (82\%) & FIVVNEF & CERFSYY \\
Gallus (64\%) & FIVINEF & CERFSYY \\
\hline
\end{tabular}




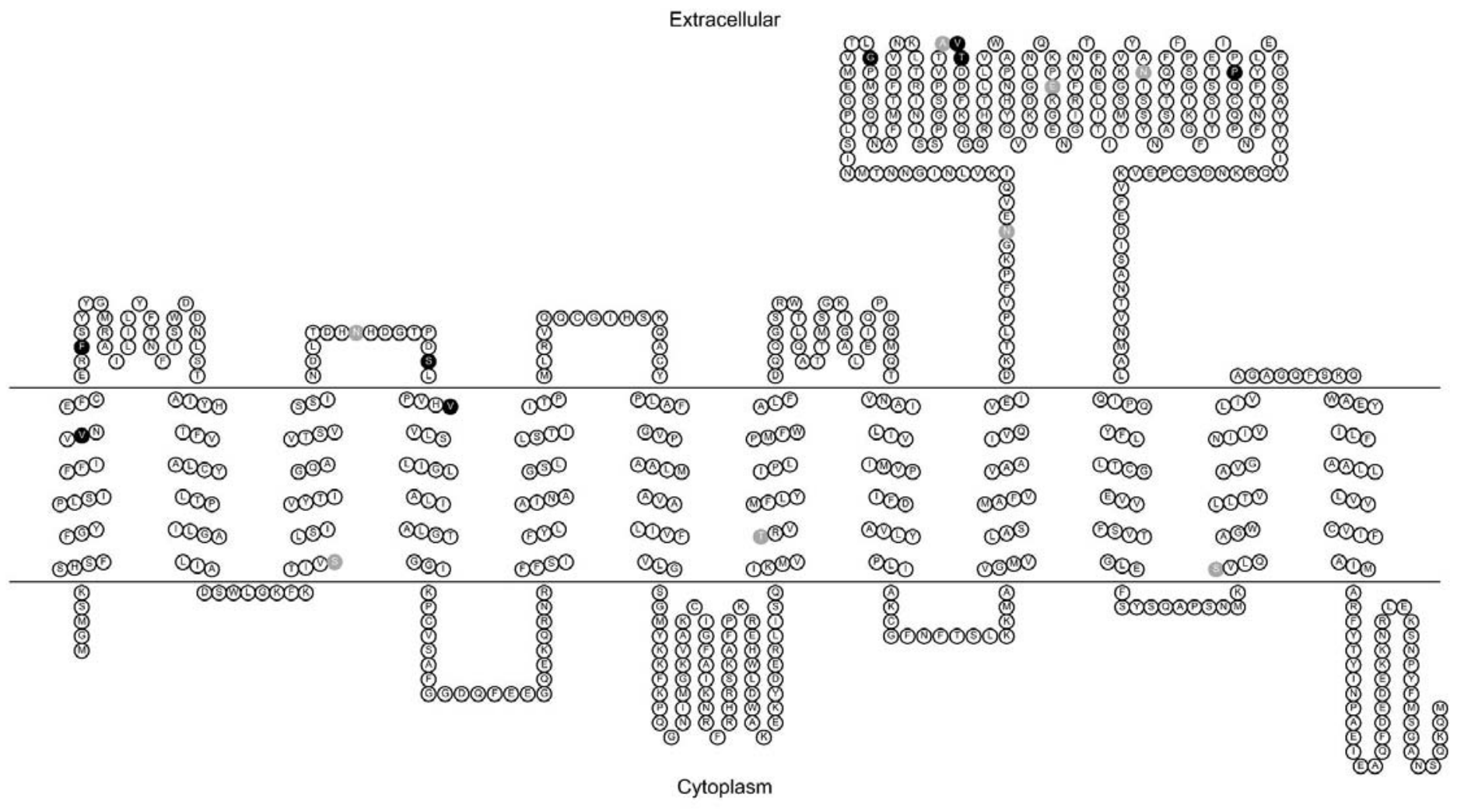

Figure 1 


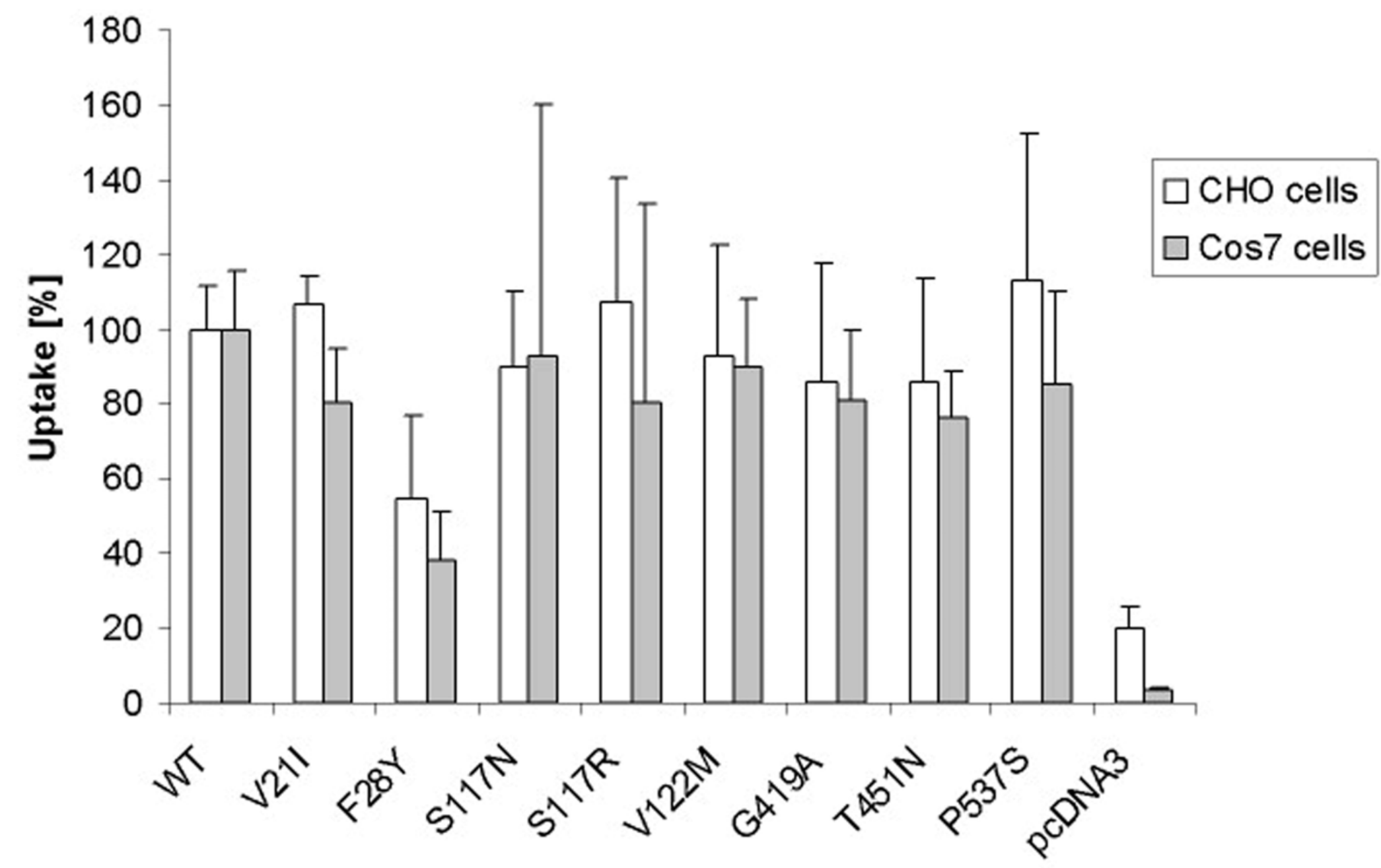

Figure 2 


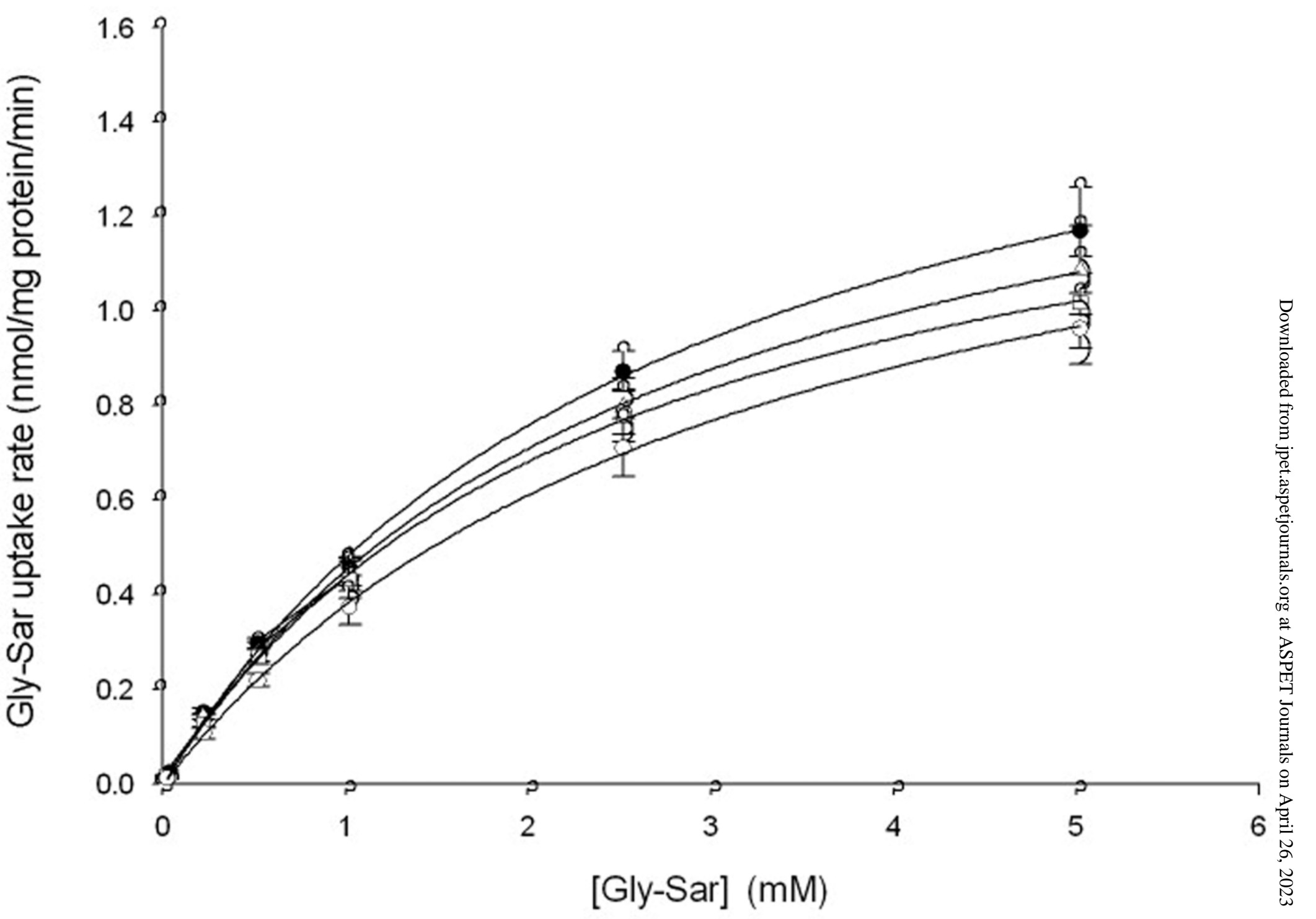

Figure 3 


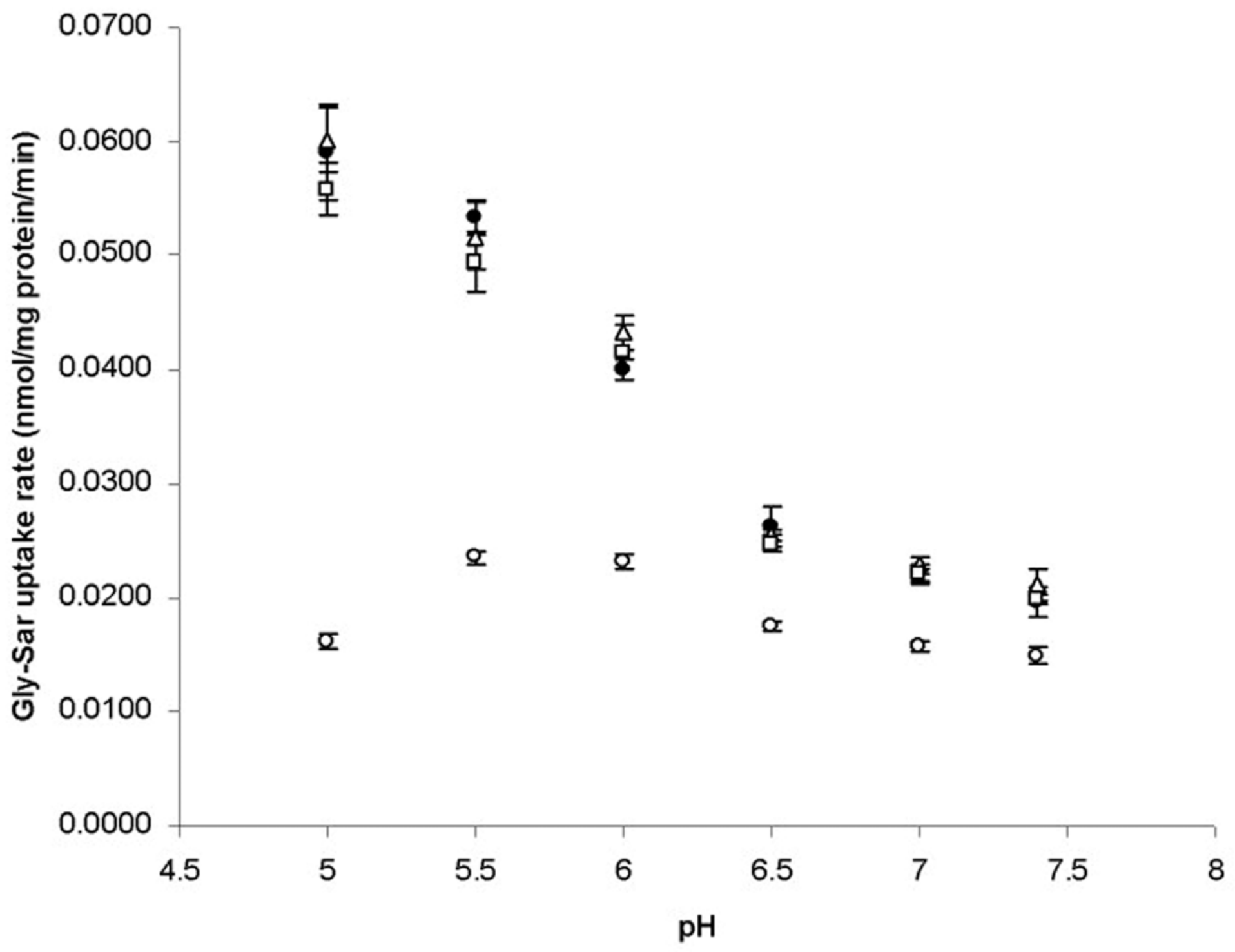


A

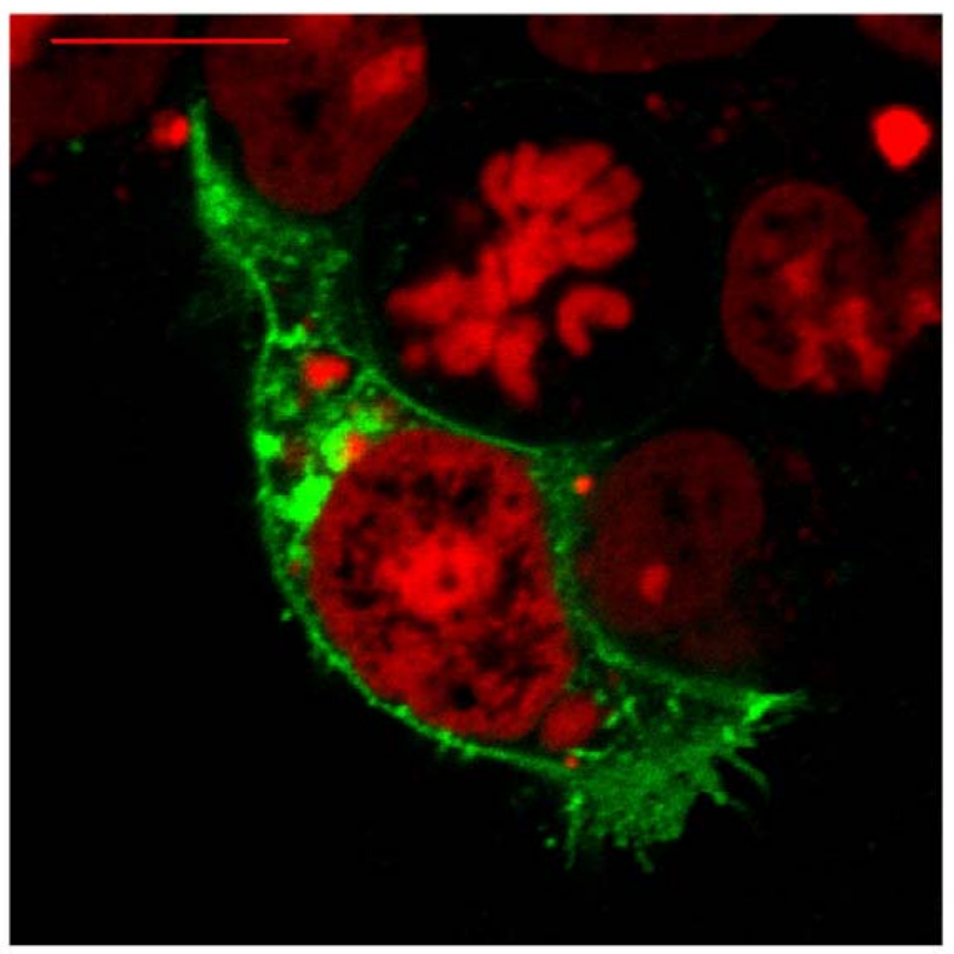

B

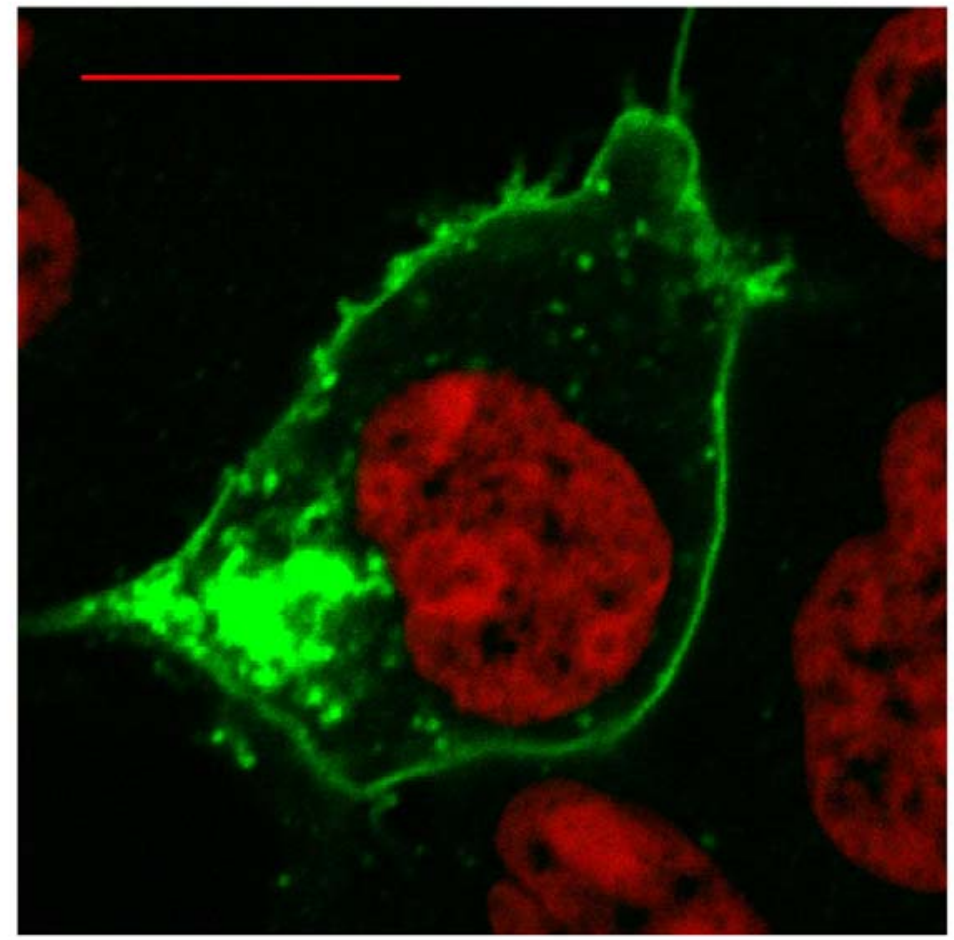

Figure 5 
JPET Fast Forward. Published on October 28, 2005 as DOI: 10.1124/jpet.105.094615

A This article has not been copyedited and formatted. The final version may differ from this version.

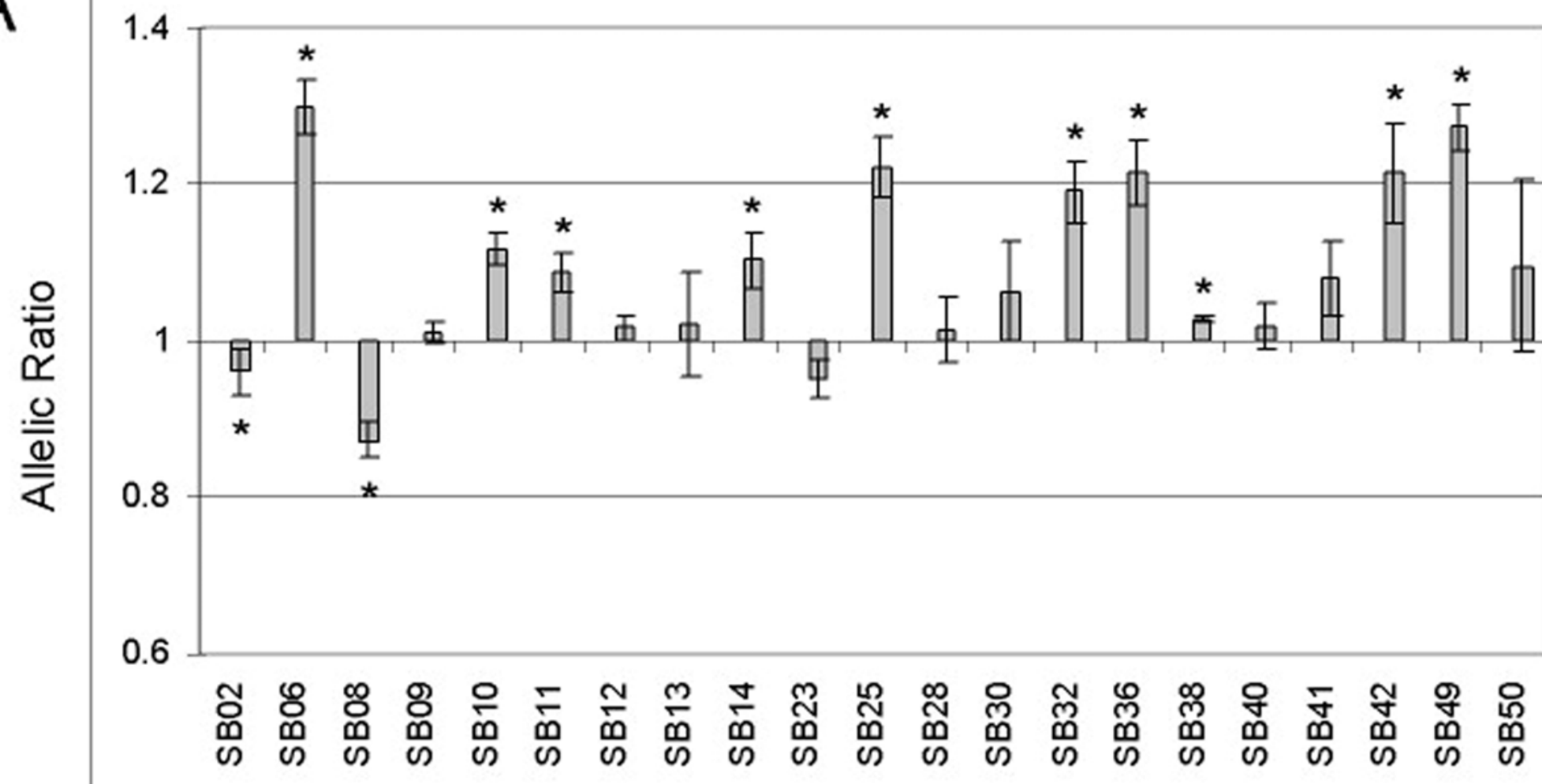

$\mathrm{B}$

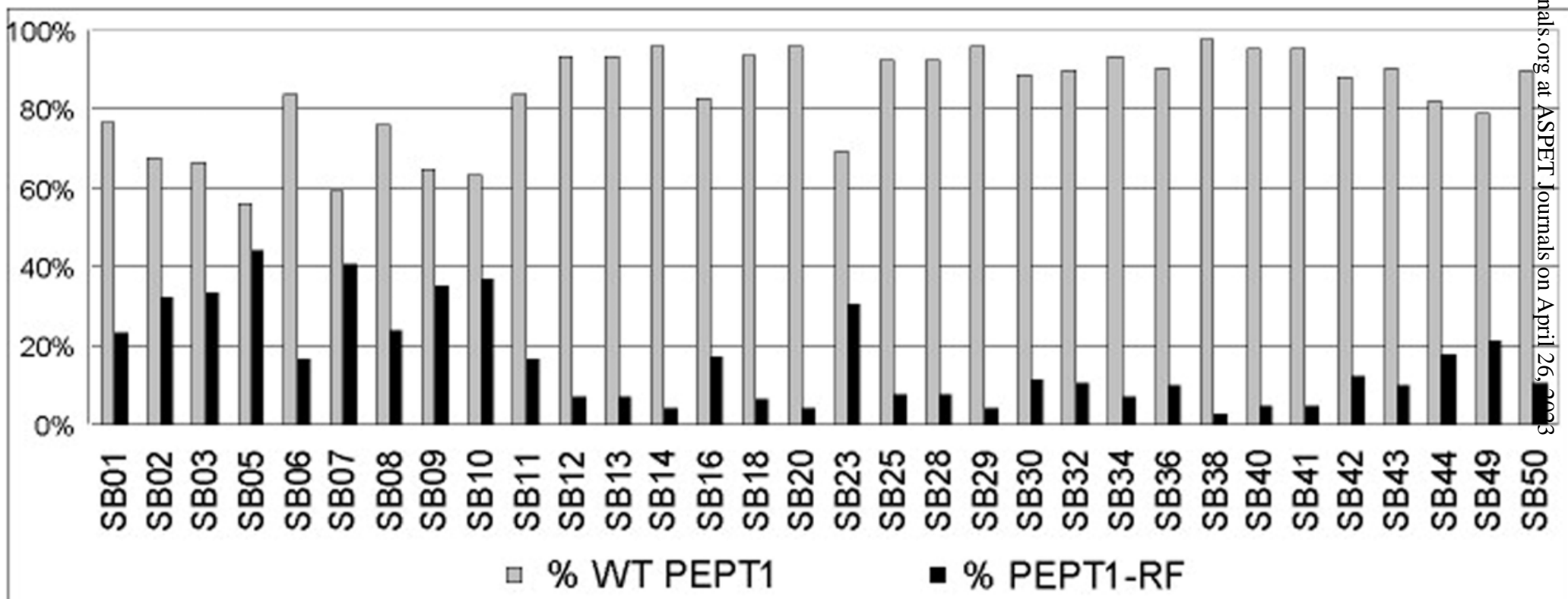

Figure 6 